\title{
Radiation response and regulation of apoptosis induced by a combination of TRAIL and CHX in cells lacking mitochondrial DNA: A role for NF-kB-STAT3-directed gene expression
}

\author{
Vladimir N. Ivanov ${ }^{*}{ }^{1}$, Shanaz A. Ghandhi ${ }^{1}$, Hongning Zhou, Sarah X. Huang, Yunfei Chai, \\ Sally A. Amundson, Tom K. Hei \\ Center for Radiological Research, Department of Radiation Oncology, College of Physicians and Surgeons, Columbia University, \\ New York, NY 10032, USA
}

A R T I C L E I N F O R M A T I O N

\section{Article Chronology:}

Received 8 December 2010

Revised version received

16 February 2011

Accepted 14 March 2011

Available online 2 April 2011

\section{Keywords:}

Mitochondria

NF-KB

STAT3

IL6

TRAIL

Apoptosis

\begin{abstract}
A B S T R A C T
Mitochondrial DNA depleted $\left(\rho^{0}\right)$ human skin fibroblasts (HSF) with suppressed oxidative phosphorylation were characterized by significant changes in the expression of 2100 nuclear genes, encoding numerous protein classes, in NF-KB and STAT3 signaling pathways, and by decreased activity of mitochondrial death pathway, compared to the parental $\rho^{+} \mathrm{HSF}$. In contrast, the extrinsic TRAIL/TRAIL-Receptor mediated death pathway remained highly active, and exogenous TRAIL in a combination with cycloheximide (CHX) induced higher levels of apoptosis in $\rho^{0}$ cells compared to $\rho^{+}$HSF. Global gene expression analysis using microarray and qRT-PCR demonstrated that mRNA expression levels of many growth factors and their adaptor proteins (FGF13, HGF, IGFBP4, IGFBP6, and IGFL2), cytokines (IL6, IL17B, IL18, IL19, and IL28B) and cytokine receptors (IL1R1, IL21R, and IL31RA) were substantially decreased after mitochondrial DNA depletion. Some of these genes were targets of NF-kB and STAT3, and their protein products could regulate the STAT3 signaling pathway. Alpha-irradiation further induced expression of several NF-kB/STAT3 target genes, including IL1A, IL1B, IL6, PTGS2/COX2 and MMP12, in $\rho^{+}$HSF, but this response was substantially decreased in $\rho^{0}$ HSF. Suppression of the IKK-NF-KB pathway by the small molecular inhibitor BMS-345541 and of the JAK2-STAT3 pathway by AG490 dramatically increased TRAIL-induced apoptosis in the control and irradiated $\rho^{+}$HSF. Inhibitory antibodies against IL6, the main activator of JAK2-STAT3 pathway, added into the cell media, also increased TRAIL-induced apoptosis in HSF, especially after alpha-irradiation. Collectively, our results
\end{abstract}

\footnotetext{
* Corresponding author. Fax: +1212305 3229.

E-mail address: vni3@columbia.edu (V.N. Ivanov).

Abbreviations: ATM, Ataxia Telangiectasia Mutated protein kinase; CHX, cycloheximide; COX-2, cyclooxygenase-2; DR4, death receptor-4; DR5, death receptor-5; EMSA, electrophoretic mobility shift assay; ERK, extracellular signal-regulated kinase; FACS, fluorescence-activated cell sorter;

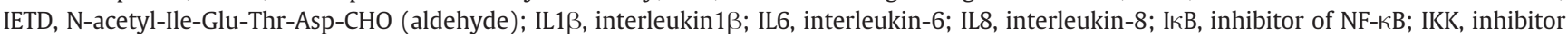
nuclear factor kappa B kinase; LEHD, N-acetyl-Leu-Glu-His-Asp-CHO (aldehyde); MAPK, mitogen-activated protein kinase; MFI, medium fluorescence intensity; NF-кB, nuclear factor kappa B; PI, propidium iodide; PI3K, phosphoinositide 3-kinase; PTGS2, prostaglandin-endoperoxide synthase 2; ROS, reactive oxygen species; TNF $\alpha$, tumor necrosis factor alpha; TRAIL, TNF-related apoptosis inducing ligand; TRAIL-R, TRAILReceptor; XIAP, X-linked inhibitor of apoptosis

1 Equal contribution.
} 
indicated that NF-KB activation was partially lost in $\rho^{0} \mathrm{HSF}$ resulting in downregulation of the basal or radiation-induced expression of numerous NF- $\mathrm{BB}$ targets, further suppressing IL6-JAK2-STAT3 that in concert with NF-KB regulated protection against TRAIL-induced apoptosis.

(c) 2011 Elsevier Inc. All rights reserved.

Introduction

The discovery of tumor necrosis factor-related apoptosis inducing ligand (TRAIL) and its receptors TRAIL-R1 (DR4/TNFRSF10A) and TRAIL-R2 (DR5/TNFRSF10B) provided an additional opportunity for cancer treatment, because TRAIL-Receptors demonstrated substantially higher levels of surface expression on many types of cancer cells compared to normal cells [1,2]. This was somewhat opposite to the distribution of Fas-Receptor and TNF-Receptors, both of which exhibit varying surface expression in normal and cancer cells. However, extensive investigation of TRAIL sensitivity among cancer cell lines indicated that almost $50 \%$ of these lines were resistant to TRAIL-induced death [3]. Numerous studies were performed on combined treatment of cancer cells to overcome their resistance to TRAIL. Different chemotherapeutic drugs, ionizing radiation, arsenic and small molecular inhibitors of signaling pathways used in a combination with TRAIL (or TRAILReceptor agonistic monoclonal antibodies) demonstrated different degrees of induction of TRAIL-induced apoptosis with promising perspectives for the clinic [4-6].

The existence of two death signaling pathways in cells, the "extrinsic" death-receptor-mediated and the "intrinsic" mitochondrial pathways highlighted the role of mitochondria in the regulation of programmed cell death $[7,8]$. Co-existence and cross-talk between these pathways in normal cells and in earlyphase cancer cells was often followed by suppression of the mitochondrial pathway in late-phase cancer cells, due to a general inhibition of mitochondrial function $[9,10]$ and a strong upregulation of gene expression of anti-apoptotic proteins of the $\mathrm{Bcl} 2$ family during cancer development [11-13].

Is there a role for the TRAIL/TRAIL-R-mediated death pathway in cells with suppressed mitochondrial functions, including malignant tumor cells? To address this question, we used a wellestablished model of $\rho^{0}$ cells, which lack mitochondrial (mt) DNA as a result of prolonged treatment of the parental $\left(\rho^{+}\right)$cells with low concentrations of ethidium bromide [14]. Two experimental models of $\rho^{0}$ cells were used in our study: human skin fibroblasts (HSF) immortalized by SV40 T-antigen and human small airway epithelial cells (SAEC) immortalized by the catalytic subunit of human telomerase (hTERT). Previous studies using similar cell systems of $\rho^{0}$ cells and the parental $\rho^{+}$cells demonstrated increased levels of some types of apoptosis in mtDNA-depleted cells in culture conditions [15] and in vivo [16], while the cytotoxic and gene-inducing effects of TNF were abrogated in these cells [17]. Even though cytochrome-c release could occur from defective mitochondria [18], there is evidence that $\rho^{0}$ cells exhibited an increased resistance to the mitochondrial apoptotic pathway [1921]. The aim of the present study was to investigate TRAIL-induced apoptosis in the context of global changes of nuclear gene expression induced by dysfunction of mitochondria in $\rho^{0}$ cells,

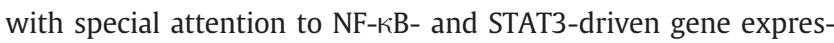
sion and the modifying effects of these changes on the regulation of TRAIL-induced apoptosis.

\section{Methods}

\section{Materials}

Human Killer-TRAIL and human Fas Ligand (FasL) were purchased from Axxora (San Diego, CA, USA). PI3K inhibitor LY294002, IKK inhibitor BMS-345541 and JAK2 inhibitor AG490 were purchased from Calbiochem/EMD Chemicals (San Diego, CA, USA).

\section{Cell culture}

Human skin fibroblasts (HSF) immortalized by SV40 T antigen [22] were maintained in a $4.5 \mathrm{~g} / \mathrm{l}$ glucose DMEM with $4 \mathrm{mM}$ L-glutamine and $100 \mathrm{mg} / \mathrm{l}$ sodium pyruvate supplemented with $10 \%$ fetal bovine serum, $100 \mathrm{IU} / \mathrm{ml}$ penicillin, and $100 \mu \mathrm{g} / \mathrm{ml}$ streptomycin. Human small airway epithelial cells immortalized by hTERT were previously established in our lab. Cells were cultured in SAGM medium. Mitochondrial ( $\mathrm{mt}$ ) DNA depleted $\rho^{0}$ cells were established from the corresponding parent $\rho^{+}$cells (HSF and SAEC) using prolonged exposure to ethidium bromide $(50 \mathrm{ng} / \mathrm{ml})$ in growth medium supplemented with $50 \mu \mathrm{g} / \mathrm{ml}$ uridine [23]. These established cultures of $\rho^{0}$ cells were further maintained in growth medium supplemented with $50 \mu \mathrm{g} / \mathrm{ml}$ uridine.

\section{Irradiation procedure and survival analysis}

Exponentially growing human skin fibroblasts (HSF) were plated in the concentric strip mylar dishes two days before irradiation to ensure a confluent state. A $50 \mathrm{cGy}$ dose of ${ }^{4} \mathrm{He}$ ions $(120 \mathrm{keV} / \mu \mathrm{m})$ was delivered to the cells using the track segment irradiation feature of the 5.5-MV Singletron accelerator at the Radiological Research Accelerator Facility of Columbia University. After irradiation at selected time points, cells were harvested and used for endpoint analysis. Non-irradiated, mock-treated control cells and $\alpha$-irradiated cells were collected $24 \mathrm{~h}$ after irradiation. Cultures were trypsinized, cell numbers were determined with a Coulter counter, and aliquots of the cells were reseeded into $100-\mathrm{mm}$ diameter dishes for colony formation. Cultures for clonogenic survival assays were incubated for 12 days, at which time they were fixed with formaldehyde and stained with Giemsa. The numbers of colonies were counted to determine the surviving fraction as described [24].

\section{Detection of mitochondrial (mt) DNA}

Mitochondrial (mt) DNA was detected in human fibroblasts using PCR with a set of primers, 5'-CCCAAACCCACTCCACCTTACTACC-3' (sense) and 5'-AGCTGTTCTTAGGTAGCTCGTCTGG-3' (antisense), designed to produce a $251 \mathrm{bp}$ mtDNA fragment. PCR amplifications were performed for 30 cycles using a DNA thermal cycler model 9700 (Perkin-Elmer). Each PCR cycle consisted of denaturation at $95{ }^{\circ} \mathrm{C}$ for $30 \mathrm{~s}$, annealing at $55^{\circ} \mathrm{C}$ for $30 \mathrm{~s}$ and extension at $72{ }^{\circ} \mathrm{C}$ for $30 \mathrm{~s}$. After the last cycle, the samples were incubated at $72{ }^{\circ} \mathrm{C}$ for an 
additional 10 min, separated by electrophoresis in 1\% agarose gels, and stained with ethidium bromide.

\section{RNA isolation and gene expression studies using microarray}

RNA isolation was performed in parallel across irradiated and nonirradiated samples. After treatment, cells were lysed at $30 \mathrm{~min}, 1 \mathrm{~h}, 4 \mathrm{~h}$ and $24 \mathrm{~h}$ time points. All experiments were done in triplicate. We analyzed the 4-h RNA by microarray hybridization. Cyanine-3 (Cy3) labeled cRNA was prepared from $0.3 \mu \mathrm{g}$ RNA using the One-Color Low RNA Input Linear Amplification PLUS kit (Agilent). Dye incorporation and cRNA yield were monitored with the NanoDrop ND-1000 Spectrophotometer (Thermo Scientific). $1.5 \mu \mathrm{g}$ of cRNA ( $>9$ pmol Cy3 per $\mu$ g cRNA) was fragmented, hybridized to Agilent Whole Human Genome Oligo Microarrays (G4112F) using the Gene Expression Hybridization Kit, and washed following Agilent's recommendations. Slides were scanned with the Agilent DNA Microarray Scanner (G2505B). Default parameters of Feature Extraction Software 9.1 (Agilent) and grid version 014850_D_F_20090416 were used for image analysis, data extraction, background correction, and flagging of non-uniform features.

Background corrected intensities were $\log _{2}$ transformed and median-normalized in BRB-Array Tools, Version 3.8.0. Nonuniform outliers or features not significantly above background intensity in $40 \%$ or more of the hybridizations were filtered out, leaving 40,472 features. A further filter requiring a minimum 1.5fold change in at least $20 \%$ of the hybridizations was then applied yielding a final set of 9066 features that were used for subsequent analyses. The microarray data are available through the Gene Expression Omnibus database using accession number GSE24945.

BRB-Array Tools was used to identify genes that were differentially expressed between sham control and irradiated cells using a random-variance paired $t$-test, an improvement over the standard $t$-test that permits sharing information among genes about within-class variation without assuming that all genes have the same variance [25]. The test compares the differences in mean log-intensities between classes relative to the expected variation in mean differences computed from the independent samples. Genes with p-values less than 0.005 were considered statistically significant. The false discovery rate (FDR) was also estimated for each gene using the method of Benjamini and Hochberg [26], to control for false positives.

\section{Quantitative real-time PCR ( $\mathrm{q} R T-P C R)$}

The High-Capacity cDNA Archive Kit (Life Technologies, Foster City, CA) was used to prepare cDNA from total RNA. A custom low-density TaqMan array (Life Technologies, Foster City, CA) was designed using validated assays and was previously described [27]. Genes for inclusion on the low-density array (LDA) were selected on the basis of differential expression and low FDR, and seven previously selected endogenous control genes [27] were also included. For gene validation studies, $100 \mathrm{ng}$ cDNA was used as input for LDAs. Quantitative real time PCR reactions were performed with the ABI 7900 Real Time PCR System using Universal PCR Master Mix (Life Technologies), with initial activation at $50{ }^{\circ} \mathrm{C}$ for $120 \mathrm{~s}$ and $94.5^{\circ} \mathrm{C}$ for $10 \mathrm{~min}$ followed by 40 cycles of $97^{\circ} \mathrm{C}$ for $30 \mathrm{~s}$ and $59.7^{\circ} \mathrm{C}$ for $60 \mathrm{~s}$. Relative fold-inductions were calculated by the $\Delta \Delta C_{T}$ method as previously used [27] using SDS version 2.3 software (Life Technologies). We applied geNorm [28] to the seven endogenous control genes on the LDAs to determine the most appropriate genes for normalizing the results. The LDA data was normalized to ubiquitin $\mathrm{C}(U B C)$ gene expression levels.

\section{Gene ontology analysis}

The genes responding significantly $(\mathrm{p}<0.005)$ to both treatments: mitochondrial depletion or irradiation were imported into PANTHER [29] and the number of genes in each functional classification category was compared against the number of genes from the NCBI human genome in that category. The binomial test was used to statistically determine over- or under-representation of PANTHER classification.

\section{Transfection and luciferase assay}

The NF- $\kappa$ B luciferase reporter containing two $\kappa \mathrm{B}$ binding sites, and STAT-Luc reporter containing three repeats of GAS sites from the Ly6A/E promoter were used to determine NF- $\kappa B$ and STAT transactivation, respectively. Transient transfection of different reporter constructs $(1 \mu \mathrm{g})$ together with pCMV- $\beta$-Galactosidase $(0.25 \mu \mathrm{g})$ into $5 \times 10^{5}$ cells was performed using Lipofectamine (Life Technologies-Invitrogen). Proteins were prepared for $\beta$-Gal and luciferase analysis $16 \mathrm{~h}$ after transfection. Luciferase activity was determined using the Luciferase assay system (Promega, Madison, WI) and was normalized based on $\beta$-galactosidase levels.

\section{FACS analysis of receptor surface levels}

Surface levels of TRAIL-R1/DR4 and TRAIL-R2/DR5 were determined by staining with the PE-labeled mAbs from eBioscience (San Diego, CA, USA). Surface levels of FAS, TNFR1, NGFR1 p75 and IL6R were determined using the PE-labeled $m A b s$ from $B D$ Pharmingen (San Jose, CA, USA). A FACS Calibur flow cytometer (Becton Dickinson, Mountain View, CA, USA) combined with the CellQuest program was used to perform flow cytometric analysis.

\section{Apoptosis studies}

Cells were exposed to soluble TRAIL $(50 \mathrm{ng} / \mathrm{ml}$ ) alone or in combination with cycloheximide $(2 \mu \mathrm{g} / \mathrm{ml})$, with sodium arsenite $(5 \mu \mathrm{M})$. Additionally, different variants of combined treatment were used, including $\alpha$-irradiation $(0.5 \mathrm{~Gy})$ followed by TRAIL treatment. Apoptosis was then assessed by quantifying the percentage of hypodiploid nuclei using FACS analysis.

\section{Immunofluorescence}

Immunofluorescence was performed as described previously [30]. Cells were grown on glass coverslips in growth medium, fixed (PBS, 4\% paraformaldehyde for $10 \mathrm{~min}$ ), permeabilized (PBS, 0.5\% Triton X-100 for $5 \mathrm{~min}$ ) and stained with antibodies to pyruvate dehydrogenase (Binding Site, United Kingdom). Secondary antibodies were obtained from Jackson ImmunoResearch. Nuclear staining was done with propidium iodide. Images were captured using a laser confocal microscope (Nikon).

\section{Western blot analysis}

Total cell lysates (50 $\mu$ g protein) were resolved on SDS-PAGE, and processed according to standard protocols. The monoclonal antibodies 
used for Western blotting included: anti-B-Actin (Sigma, St. Louis, MO, USA); anti-FLIP (NF6) (Axxora); anti-phospho-p53 (Ser15); antiSmac/Diablo; anti-p21 Waf1/Cip1; anti-caspase-8, anti-caspase-3 (Cell Signaling); anti-XIAP (BD Biosciences); anti-COX2 (Cayman Chemical). The polyclonal antibodies used included: anti-total p53; anti-phospho-p44/p42 MAP kinase (Thr202/Tyr204) and anti-p44/ p42 MAP kinase; anti-phospho-AKT (Ser473) and anti-AKT; antiPARP; anti-BAX, anti-Bcl-xL (Cell Signaling); anti-Survivin (R\&D). The secondary antibodies were conjugated to horseradish peroxidase; signals were detected using the ECL system (Thermo Scientific, Rockford, IL, USA).

\section{ELISA}

Antibody pairs used in sandwich ELISA for this study were all commercially available. Kits to detect IL6, TNF $\alpha$ and IL1 $\beta$ were from Invitrogen.

\section{Determination of cytochrome-c oxidase enzymatic activity}

Biochemical assays for cytochrome-c oxidase activity were done as described [20]. Briefly, cells in log phase of growth were collected and re-suspended in $50 \mathrm{mM}$ potassium phosphate ( $\mathrm{pH}$ 7.0). Cells were lysed by two cycles of freezing and thawing. Cell lysates were treated with $1.3 \mathrm{mM}$ lauryl maltoside before enzymatic measurements. Cytochrome-c oxidase activity was assessed by measuring the oxidation of reduced cytochrome $\mathrm{c}$ at $550 \mathrm{~nm}$ (nmol oxidized cytochrome $c$ per min per mg protein).

\section{Determination of caspase-8, caspase-9 and caspase-3 enzymatic activities}

Enzymatic activities of caspase-8, caspase- 9 and caspase- 3 in total cell lysates prepared before and after apoptotic stimulation of HSF was determined using R\&D caspase colorimetric assay with IETDpNA, LEHD-pNA and DEVD-pNA substrates, respectively.

\section{Oxygen consumption}

Oxygen consumption in intact cells was assayed as described previously [30]. Briefly, $1 \times 10^{7}$ cells were suspended in $1.5 \mathrm{ml}$ of DMEM lacking glucose, and oxygen concentration was assayed over 3 min at $37^{\circ} \mathrm{C}$ in a Hansatech (MA) Clark's oxygen electrode unit.

\section{Statistical analysis}

Data from 3 to 4 independent experiments were calculated as means and standard deviations. Comparisons of results between treated and control groups were made by the Student's t-tests. A p-value of 0.05 or less between groups was considered significant.

\section{Results}

Global gene expression in mtDNA-depleted human fibroblasts

Mitochondria play a crucial role in regulation of numerous cell functions, including energy production, stress response and programmed cell death. To investigate mitochondria-dependent mech- anisms controlling death receptor (TRAIL-R and FAS) mediated apoptosis, in the present study we used mitochondrial (mt) DNA depleted $\left(\rho^{0}\right)$ human skin fibroblasts (HSF) and their parental $\rho^{+}$HSF. HSF are known to produce pro-inflammatory cytokines in a NF-kBdependent manner and to facilitate tumor-promoting inflammation [31]. Depletion of mtDNA in HSF after prolonged incubation with ethidium bromide was detected by PCR with the corresponding primers (Fig. 1A). The critical characteristic of $\rho^{0} \mathrm{HSF}$ was the dramatic suppression of general mitochondrial function, due to the absence of mtDNA encoding rRNAs, tRNAs and 13 polypeptides, including three cytochrome-c oxidase subunits [32]. It was accompanied by inhibition of cytochrome-c oxidase enzymatic activity (Fig. 1B), inhibition of oxidative phosphorylation and suppression of mitochondrial membrane potential (Fig. 1C) linked with strong down-regulation of oxygen consumption (Fig. 1D). At the morphological level, the mitochondrion was present in $\rho^{0}$ cells with decreased expression of nuclear DNA-encoded mitochondrial proteins, such as pyruvate dehydrogenase (Fig. 1C).

Comparison of $\rho^{0}$ and normal fibroblast gene expression by whole genome microarray profiling showed that mitochondrial depletion significantly changed the gene expression levels of 2100 genes (with false discovery rate $<0.04$ ) (Fig. 2A and Suppl. Table 1). Ontology analyses showed that changes in gene expression were highly enriched in functions affected signaling molecules (134 genes, p-value $10^{-10}$ ), extracellular matrix proteins ( 60 genes, $\mathrm{p}$-value $10^{-6}$ ), transcription factors ( 179 genes, p-value $10^{-5}$ ) and a broad range of metabolic enzymes (Fig. 2B). Of the 2100 genes, 53\% were suppressed after mitochondrial depletion and gene ontology showed that there was significant enrichment in number of suppressed genes for the PANTHER protein class of oxidoreductases ( $\mathrm{p}$-value $10^{-3}$ ), which includes proteins involved in electron transport and oxidative phosphorylation (Table 1 and Suppl. Table 1). Expression levels of the master regulators of mitochondriogenesis, PPARGC1A (Peroxisome proliferator-activated receptor gamma, coactivator 1) were dramatically decreased in $\rho^{0}$ fibroblasts (Table 1 ). Additionally, expression of many growth factors, growth factor adaptor proteins (FGF13, HGF, IGFBP4, IGFBP6, and IGFL2), cytokines (IL6, IL17B, IL18 IL19, and IL28B), cytokine receptors (IL1R1, IL21R, and IL31RA) and downstream targets (IL1RAP2 and TNFAIP6) was substantially decreased in $\rho^{0}$ HSF versus normal HSF (Table 1).

Furthermore, a class of negatively regulated genes contained some members of the tumor necrosis factor receptor superfamily, metabolic enzymes of different subclasses (not only oxidoreductases, but also urokinase, protein kinase $\mathrm{C}$-theta and others) and many transcription factors, including NF-ATc1 (Table 1 and Suppl. Table 1). A common feature of several genes (IL6, IL17B, IL31RA, PTGES, TNFAIP6, S100A3, and S100A4) with downregulated expression in $\rho^{0} \mathrm{HSF}$ was a role for transcription factor NF- $\mathrm{KB}$ in the control of their expression (http:// people.bu.edu/gilmore/nf-kb/target/index.html). Furthermore, IL19, IL24 and IL28 mRNA levels were also decreased in $\rho^{0}$ HSF. The corresponding cytokines (IL6, IL19, IL24 and IL28) could be involved in autocrine/paracrine regulation of JAK2-STAT3 signaling pathway, while active STAT3 is known to control numerous genes, including COX2, EGFR1, several interleukin receptors, Cyclin A1 and Cyclin D3 and general cell survival and proliferation [33,34]. Interestingly, several NFkB-dependent genes (GADD45-alpha, IL8 and TNFAIP3) (http://people bu.edu/gilmore/nf-kb/target/index.html) demonstrated upregulated levels of expression in mtDNA-depleted cells (Table 2 and Suppl. Table 1). However, TNFAIP3 encoding protein A20 is actually known as 
A Human Skin Fibroblasts (HSF)
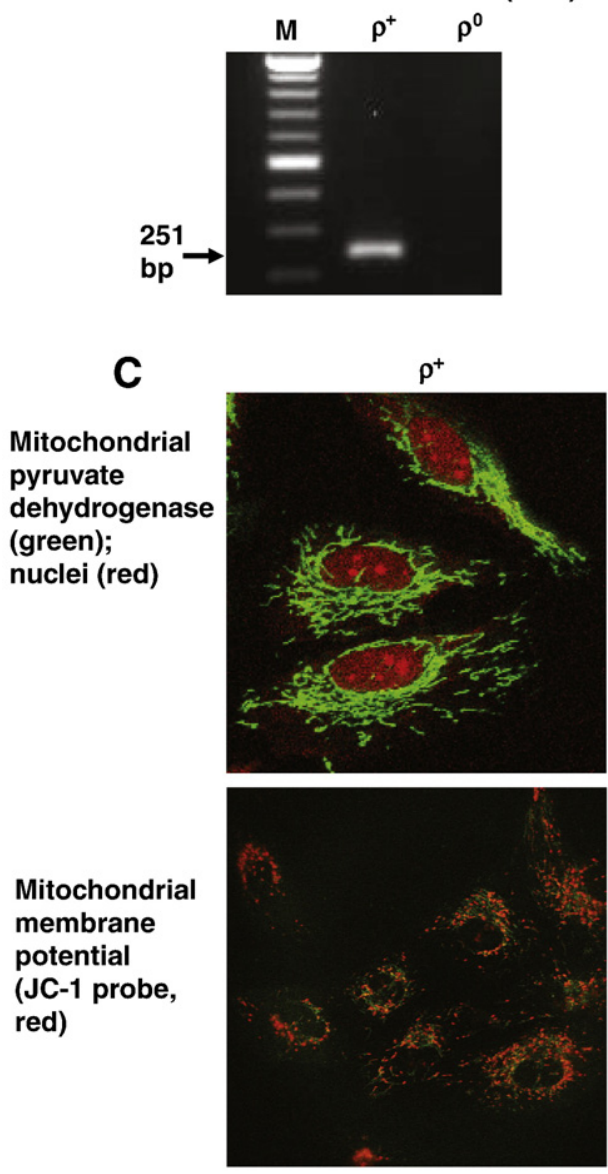

D
B
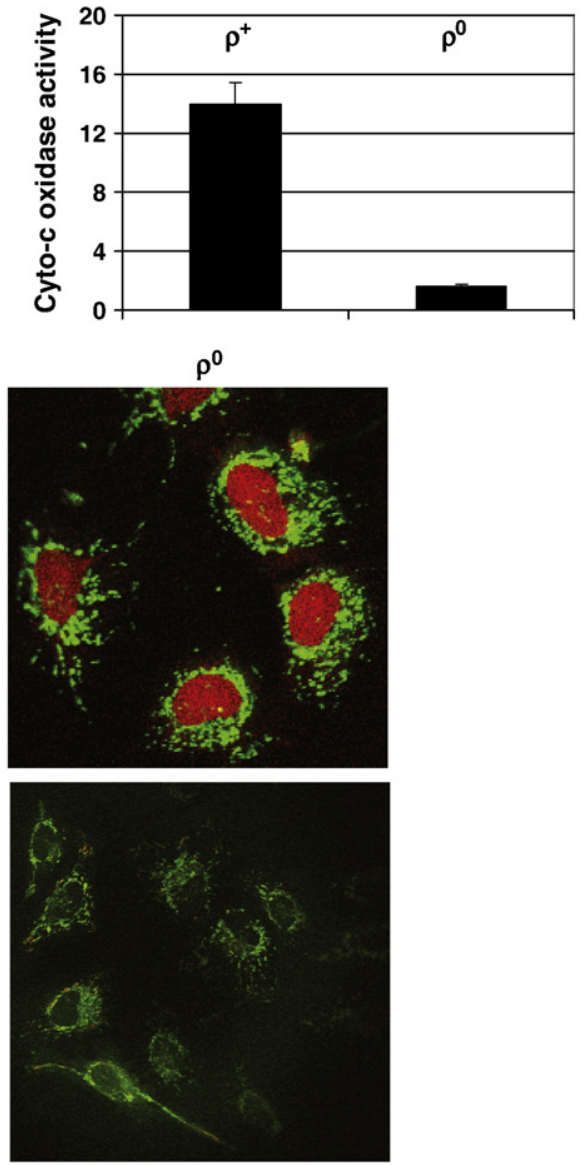

$\rho^{0}$

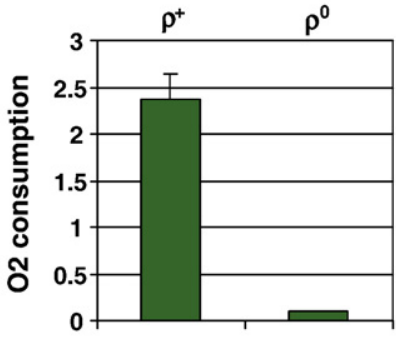

Fig. 1 - Mitochondrial (mt)DNA-depleted human skin fibroblasts (HSF $\rho^{0}$ ) and their parental cells (HSF $\rho^{+}$). A. PCR amplification of the mtDNA fragment (251 bp) from HSF $\rho^{+}$using mtDNA primer set. B. Cytochrome-c oxidase activity (oxidized cytochrome-c, $\mathrm{nmol} / \mathrm{min} / \mathrm{mg}$ protein) in total cell extracts from $\rho^{+}$and $\rho^{0}$ cells was determined as described in "Methods". C. Immunofluorescence of mitochondrial pyruvate dehydrogenase (green) with PI-stained red nuclei in $\rho^{+}$and $\rho^{0}$ cells. Mitochondrial membrane potential was detected using JC-1 probe based on change of green to red fluorescence. D. Rates of oxygen consumption (femtomole/cell/min) for $\rho^{+}$and $\rho^{0}$ cells were determined using an oxygen electrode unit.

a suppressor of NF-kB activation, due to its de-ubiquitinating activity [35]. Furthermore, genes with increased expression levels included

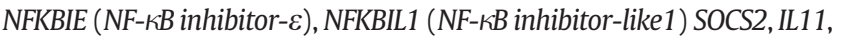
EGFR1 and TLR3 and 4 (Toll-like Receptors 3 and 4), which might regulate the NF- $\kappa$ B and STAT3 signaling pathways in both negative and positive directions. On the other hand, the upregulation of HIF1A, GSTA2 and TF (Transferrin) gene expression in hypoxic conditions of mtDNA-depleted cells was quite expected (Table 2). Importantly, HIF1 has been previously demonstrated as a critical transcriptional regu- lator, which induced strong activation of glycolysis and suppressed the Krebs cycle and mitochondrial respiration in cancer cells [36].

The family of genes encoding KRAB-zinc finger proteins was also enriched in the 2100 genes that were changed in $\rho^{0}$ cells. KRAB-zinc finger proteins are transcriptional regulators, and we found that mitochondrial depletion caused the up-regulation of expression of 67 members of this family (Suppl. Table 1 ). Recently, Zinc finger protein 10 (ZNF10), a member of this family, has been shown to cause long-range repression of genes, which was 


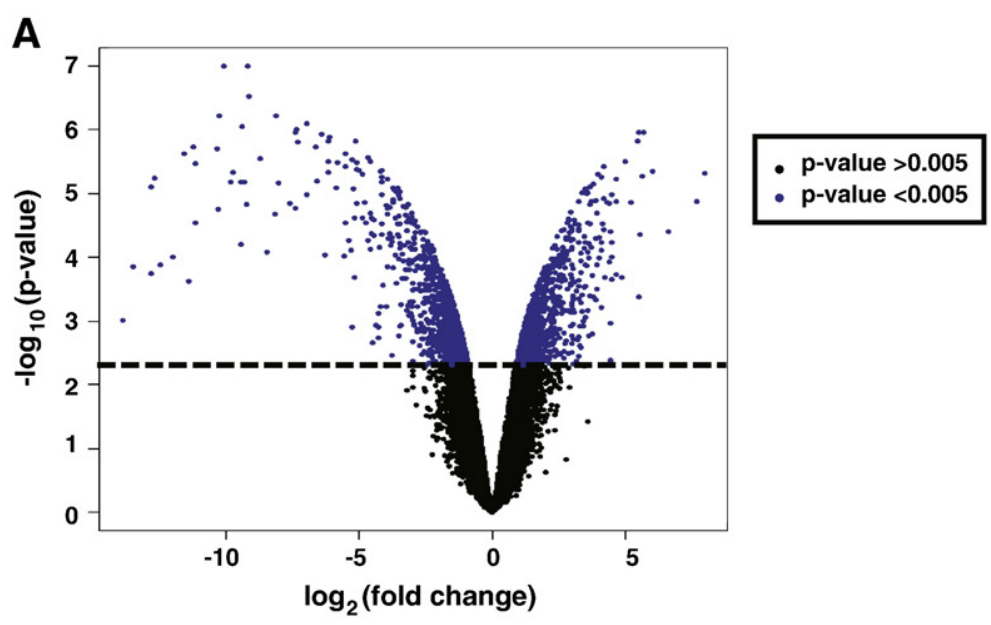

\begin{tabular}{|c|c|c|}
\hline PANTHER Protein Class & number of genes & p-value \\
\hline signaling molecule & 134 & 0.0000000002 \\
\hline growth factor & 30 & 0.000004 \\
\hline extracellular matrix protein & 60 & 0.000004 \\
\hline cell adhesion molecule & 76 & 0.00001 \\
\hline receptor & 161 & 0.00001 \\
\hline extracellular matrix structural protein & 25 & 0.00001 \\
\hline transcription factor & 179 & 0.00004 \\
\hline protease inhibitor & 27 & 0.00004 \\
\hline serine protease inhibitor & 19 & 0.0002 \\
\hline type I cytokine receptor & 12 & 0.0002 \\
\hline calcium-binding protein & 41 & 0.0004 \\
\hline oxidoreductase & 66 & 0.001 \\
\hline aminoacyl-tRNA synthetase & 8 & 0.002 \\
\hline cell junction protein & 21 & 0.003 \\
\hline transferase & 125 & 0.003 \\
\hline glycosyltransferase & 26 & 0.004 \\
\hline hydrolase & 147 & 0.01 \\
\hline DNA methyltransferase & 5 & 0.01 \\
\hline metalloprotease & 26 & 0.01 \\
\hline dehydrogenase & 28 & 0.01 \\
\hline cytokine & 19 & 0.01 \\
\hline annexin & 17 & 0.01 \\
\hline defense/immunity protein & 60 & 0.01 \\
\hline cytokine receptor & 30 & 0.01 \\
\hline nucleic acid binding & 150 & 0.01 \\
\hline reductase & 22 & 0.01 \\
\hline structural protein & 28 & 0.02 \\
\hline basic helix-loop-helix transcription factor & 14 & 0.02 \\
\hline metalloprotease inhibitor & 2 & 0.03 \\
\hline guanyl-nucleotide exchange factor & 17 & 0.03 \\
\hline chemokine & 7 & 0.04 \\
\hline serine protease & 29 & 0.04 \\
\hline protein kinase & 44 & 0.04 \\
\hline
\end{tabular}

Fig. 2 - Differentially expressed genes in mtDNA-depleted human skin fibroblasts (HSF $\rho^{0}$ ) compared with their parental cells $\left(\right.$ HSF $\left.\rho^{+}\right)$. A. Comparison of gene expression was performed using microarrays. The log transformed fold change in relative gene expression is plotted on the $x$-axis and the log transformed $p$-value is plotted on the $y$-axis. Each point in the graph represents an individual gene. Genes toward the top of the graph have a lower p-value and the genes further to the left and the right of the $x$-axis have greater fold change between classes. From paired class comparison of HSF $\rho^{0}$ and HSF $\rho^{+}$gene expression, there were 2100 genes that were differentially expressed between the two conditions, FDR $<0.04$. B. Gene ontology analysis using PANTHER showing functional enrichment of genes, number of genes in each protein class is indicated out of the 2100 differentially expressed genes. Categories are ordered by significance (p-values).

associated with heterochromatin spreading [37]. We observed in our study that ZNF10 gene expression was up-regulated 5-fold in $\rho^{0}$ cells (Table 2 ) that could have implication for the changes in gene expression patterns. Taken together, our results demonstrat- ed numerous changes in nuclear gene expression in mtDNAdepleted cells versus normal fibroblasts with a potential role for NF-KB- and STAT3-directed transcription among many other transcriptional activators and repressors. Consequently, the 
Table 1 - Downregulated gene expression in mtDNA-depleted human skin fibroblasts.

\begin{tabular}{|c|c|c|c|c|}
\hline \multirow[t]{2}{*}{ Gene name } & \multirow{2}{*}{$\begin{array}{c}\text { Gene } \\
\text { symbol }\end{array}$} & \multirow{2}{*}{$\begin{array}{l}\text { Probe } \\
\text { ID }\end{array}$} & Fold change & \multirow[t]{2}{*}{ p-value } \\
\hline & & & $\overline{\mathrm{Rho0} / \mathrm{HSF}+}$ & \\
\hline Cytochrome b5 reductase 2 (CYB5R2), mRNA & CYB5R2 & 2966 & 0.14 & $7.44 \mathrm{E}-05$ \\
\hline Cytochrome b-c1 complex subunit 3 (Complex III subunit 3) & CYTB & 8924 & 0.00081 & $6.00 \mathrm{E}-07$ \\
\hline Fibroblast growth factor 13 (FGF13), transcript variant 1 & FGF13 & 17893 & 0.1 & $1.58 \mathrm{E}-05$ \\
\hline Hepatocyte growth factor (HGF), transcript variant 2 & HGF & 1587 & 0.19 & 0.0004288 \\
\hline Insulin-like growth factor binding protein 4 (IGFBP4) & IGFBP4 & 40120 & 0.4 & 0.0025358 \\
\hline Insulin-like growth factor binding protein 6 (IGFBP6) & IGFBP6 & 7912 & 0.29 & 0.0003373 \\
\hline IGF-like family member 2 (IGFL2), transcript variant 1 & IGFL2 & 7158 & 0.29 & 0.0018106 \\
\hline Inhibitor of kappa B, kinase epsilon (IKBKE) & IKBKE & 16178 & 0.41 & $7.12 \mathrm{E}-05$ \\
\hline Interleukin 17B (IL17B) & IL17B & 16507 & 0.29 & 0.0008358 \\
\hline Interleukin 18 (interferon-gamma-inducing factor) (IL18) & IL18 & 914 & 0.048 & 0.0011637 \\
\hline Interleukin 19 (IL19), transcript variant 1 & IL19 & 12452 & 0.19 & 0.001338 \\
\hline Interleukin 1 receptor, type I (IL1R1) & IL1R1 & 31100 & 0.33 & 0.0006962 \\
\hline Interleukin 1 receptor accessory protein-like 2 (IL1RAPL2) & IL1RAPL2 & 8613 & 0.28 & 0.004756 \\
\hline Interleukin 21 receptor (IL21R), transcript variant 2 & IL21R & 31421 & 0.043 & $2.46 \mathrm{E}-05$ \\
\hline Interleukin 24 (IL24), transcript variant 1 & IL24 & 21732 & 0.22 & 0.0001206 \\
\hline Interleukin 28B (IL28) (interferon, lambda 3) & IL28B & 25800 & 0.33 & 0.0023302 \\
\hline Interleukin 31 receptor A (IL31RA) & IL31RA & 33280 & 0.18 & 0.0009293 \\
\hline Interleukin 6 (interferon, beta 2) (IL6) & IL6 & 9255 & 0.43 & 0.0040936 \\
\hline Mitogen-activated protein kinase kinase kinase 8 (MAP3K8) & МАРЗК8 & 8124 & 0.29 & 0.004285 \\
\hline Metallothionein 1M (MT1M) & MT1M & 29528 & 0.046 & $4.60 \mathrm{E}-05$ \\
\hline Nuclear factor of activated T-cells, cytoplasmic 1 (NF-ATC1) & NFATC1 & 22496 & 0.12 & $6.95 \mathrm{E}-05$ \\
\hline Plasminogen activator, urokinase (PLAU) & PLAU & 1130 & 0.057 & $4.40 \mathrm{E}-05$ \\
\hline Peroxisome proliferator-activated receptor gamma, coactivator 1 & PPARGC1A & 7742 & 0.17 & 0.0003335 \\
\hline Protein kinase $\mathrm{C}$, theta (PRKCQ) & PRKCQ & 33583 & 0.32 & 0.0011877 \\
\hline Prostaglandin E synthase (PTGES) & PTGES & 33403 & 0.39 & 0.0007839 \\
\hline Ribosomal protein S6 kinase-like 1 (RPS6KL1) & RPS6KL1 & 14792 & 0.25 & 0.0035587 \\
\hline Transforming growth factor, beta-induced, 68 kDa (TGFBI) & TGFBI & 22104 & 0.43 & 0.0049484 \\
\hline Tumor necrosis factor, alpha-induced protein 6 (TNFAIP6) & TNFAIP6 & 31876 & 0.066 & $6.00 \mathrm{E}-06$ \\
\hline Tumor necrosis factor receptor superfamily, member 10a (TNFRSF10A) & TNFRSF10A & 15317 & 0.41 & 0.0011807 \\
\hline Tumor necrosis factor receptor superfamily, member 19 (TNFRSF19) & TNFRSF19 & 28863 & 0.21 & 0.0010152 \\
\hline
\end{tabular}

regulation of expression of individual genes in mtDNA-depleted cells was dependent on cooperative effects of many signaling pathways and the corresponding transcription factors with costimulatory or co-inhibitory functions.

\section{Radiation response and inducible $\mathrm{NF- \kappa B/STAT3-dependent}$ gene expression in mtDNA-depleted human skin fibroblasts}

Ionizing radiation and chemotherapy are two predominant therapeutic modalities for cancer treatment. Ionizing radiation is known to coordinately activate expression of large number of individual genes controlling numerous functions, including cell survival and cell death [38,39]. We used $\alpha$-particle irradiation $(0.5 \mathrm{~Gy})$ of normal and mtDNA-depleted fibroblasts to further elucidate the regulatory role of mitochondria in radiation response that might dramatically affect cell proliferation and survival. We performed global analysis of gene expression in $\rho^{0}$ and $\rho^{+}$HSF $4 \mathrm{~h}$ after exposure to $\alpha$-irradiation $(0.5 \mathrm{~Gy})$ using microarrays and found that expression of 142 genes in $\rho^{+}$HSF and 126 genes in $\rho^{0}$ HSF responded to irradiation (pvalue $<0.005$ ) (Suppl. Tables 2 and 3 ). Interestingly, we found a few genes that showed upregulation of expression in $\rho^{+}$and downregulation in $\rho^{0}$ cells after irradiation; however, very few genes showed the opposite pattern (top and bottom of the heatmap, Fig. 3A, the left side). Gene ontology analysis confirmed substantial differences in the radiation response of $\rho^{0}$ versus $\rho^{+}$HSF that affected differentially critical biological processes and showed significant enrichment in the number of genes, which regulate signaling and communication processes in the $\rho^{0}$ cells after irradiation, while cellular defense processes were implicated in the normal cell radiation response (Figs. 3A-C). Among these genes, several NF-kB targets (IL31RA, MMP12, PTGS2/COX2) demonstrated substantially decreased mRNA levels in $\rho^{0}$ HSF compared to $\rho^{+}$HSF $4 \mathrm{~h}$ after irradiation (Fig. 3C). The corresponding receptor proteins, products of IL31RA and IL2RG genes, are known to participate in JAK-STAT3 activation; consequently, suppression of these genes in $\rho^{0}$ HSF after exposure to radiation might cause serious disturbance of this pathway.

Using qRT-PCR for additional analysis and validation of radiationinduced changes in gene expression in extended time frame $0.5-24 \mathrm{~h}$ after treatment, we further observed that $\alpha$-particle irradiation increased expression levels of the numerous NF-kB transcriptional targets in $\rho^{+}$HSF with different kinetics for individual genes. Importantly, NF-KB-driven pro-inflammatory signature genes, IL1A, IL1B, IL6, IL8, IL33, PTGS2/COX2, MMP1 and MMP3 exhibited substantial upregulation of expression at time points between $0.5 \mathrm{~h}$ and $24 \mathrm{~h}$ after irradiation that was partially suppressed in mtDNA-depleted cells (Figs. 4A and B). Furthermore, a class of NF- $\mathrm{BB}$ target genes with differential kinetics of expression after exposure to irradiation of $\rho^{0}$ and $\rho^{+}$HSF included DNA repair/cell cycle regulator GADD45A, superoxide dismutase (SOD2), cyclin-dependent kinase inhibitor $1 \mathrm{~A}$ (CDKN1A, p21-Cip1), as well as, CXCL2, CXCL3 and CXCL5 (Fig. 4A). TNFR1(TNFRSF1) gene expression was only marginally regulated by $\alpha$ irradiation in HSF (Fig. 4B). Finally, expression of IL6 gene (Figs. 4A and B) was followed by increased IL6 secretion into the cell media $48 \mathrm{~h}$ after exposure of HSF to $\alpha$-particles. This secretion was substantially 
Table 2 - Upregulated gene expression in mtDNA depleted HSF.

\begin{tabular}{|c|c|c|c|c|}
\hline \multirow[t]{2}{*}{ Gene name } & \multirow{2}{*}{$\begin{array}{c}\text { Gene } \\
\text { symbol }\end{array}$} & \multirow{2}{*}{$\begin{array}{l}\text { Probe } \\
\text { ID }\end{array}$} & Fold change & \multirow[t]{2}{*}{ p-value } \\
\hline & & & Rho0/HSF+ & \\
\hline Bcl2 transcript variant alpha & BCL2 & 7248 & 2.44 & 0.0011768 \\
\hline BCL2-like 11 (apoptosis facilitator) (BCL2L11)/BIM, transcript variant 1 & BCL2L11 & 29712 & 2.27 & 0.0040615 \\
\hline CCAAT/enhancer binding protein (C/EBP), alpha (CEBPA) & CEBPA & 8875 & 4.94 & 0.0010589 \\
\hline CCAAT/enhancer binding protein (C/EBP), gamma (CEBPG) & CEBPG & 100 & 3.3 & 0.0003227 \\
\hline E2F transcription factor 3 (E2F3) & E2F3 & 34560 & 2.43 & 0.0014849 \\
\hline Epidermal growth factor receptor, transcript 1 & EGFR & 7505 & 2.12 & 0.0030475 \\
\hline Fibroblast growth factor 12 (FGF12), transcript variant 2 & FGF12 & 26299 & 3.43 & 0.0002985 \\
\hline GADD45-alpha & GADD45A & 33558 & 2.61 & 0.0031693 \\
\hline Glutathione S-transferase alpha 2 (GSTA2) & GSTA2 & 26996 & 3.4 & 0.0008577 \\
\hline Hypoxia inducible factor 1 , alpha subunit (HIF1A) & HIF1A & 2124 & 2.02 & 0.0037596 \\
\hline Harakiri, Bcl2 interacting protein & HRK & 31305 & 12.45 & $6.08 \mathrm{E}-05$ \\
\hline Interleukin 11 (IL11) & IL11 & 14082 & 2.96 & 0.0031661 \\
\hline Interleukin 13 receptor, alpha 2 (IL13RA2) & IL13RA2 & 10906 & 22.09 & 0.0040849 \\
\hline Interleukin 18 receptor 1 (IL18R1) & IL18R1 & 11707 & 7.51 & 0.0006791 \\
\hline Interleukin-6 receptor beta chain & IL6ST & 29182 & 2.05 & 0.0036609 \\
\hline Interleukin 8 (IL8) & IL8 & 6975 & 6.55 & 0.0006952 \\
\hline NFKB inhibitor epsilon & NFKBIE & 34721 & 2.04 & 0.0030544 \\
\hline NFKB inhibitor-like 1 (NFKBIL1) & NFKBIL1 & 12738 & 2.44 & 0.0014225 \\
\hline Suppressor of cytokine signaling 2 (SOCS2) & SOCS2 & 37662 & 2.31 & 0.0018985 \\
\hline TEK tyrosine kinase, endothelial (TEK) & TEK & 7294 & 13.32 & $6.97 \mathrm{E}-05$ \\
\hline Transferrin (TF) & $\mathrm{TF}$ & 2594 & 6.77 & 0.0023108 \\
\hline Toll-like receptor 3 (TLR3) & TLR3 & 13279 & 3.42 & 0.001027 \\
\hline Toll-like receptor 4 (TLR4), transcript variant 1 & TLR4 & 1711 & 4.62 & 0.0007938 \\
\hline Tumor necrosis factor, alpha-induced protein 3 (TNFAIP3) & TNFAIP3 & 2743 & 2.31 & 0.002519 \\
\hline Tumor necrosis factor receptor superfamily, member 11a (TNFRSF11a) & TNFRSF11A & 38575 & 3.73 & 0.0004463 \\
\hline Tumor necrosis factor receptor superfamily, member 21 (TNFRSF21) & TNFRSF21 & 32413 & 2.47 & 0.0011732 \\
\hline Tumor necrosis factor (ligand) superfamily, member 13b (TNFSF13B) & TNFSF13B & 18553 & 1.95 & 0.0048793 \\
\hline Zinc finger protein 10 (ZNF10) & ZNF10 & 13608 & 5.19 & 0.0001083 \\
\hline Zinc finger protein 528 (ZNF528) & ZNF528 & 35665 & 11.77 & $1.03 \mathrm{E}-05$ \\
\hline
\end{tabular}

downregulated in mtDNA-depleted HSF (Fig. 4C). Increased secretion of IL1ß (2-fold) after irradiation was also observed for normal, but not for mtDNA-depleted HSF (data not shown). Collectively, these results indicated a special role for induction of NF- $\mathrm{KB}$ activity in the regulation of the cellular radiation response and a connection between mitochondrial function and NF- $\kappa \mathrm{B}$ activation based on substantial differences between expression of NF- $\kappa$ B target genes in $\rho^{0}$ and $\rho^{+}$ HSF.

\section{Characterization of the main signaling pathways in normal and mtDNA-depleted human fibroblasts following irradiation}

A typical pattern of radiation-induced signaling pathways in HSF includes: i) DNA-damage-induced activation of ATM followed by ATM-dependent p53-Ser15 phosphorylation (Figs. 5A and B); ii) activation of MAPK pathways (Fig. 5A); iii) a complex regulation of NF-KB transacting activity (Fig. $5 \mathrm{C}$ ) probably through both the endogenous ATM-directed and the secondary ligand/receptor routes (such as TNF/TNFR1, FASL/FAS, TRAIL/TRAIL-R1/R2, IL1 $\beta /$ IL1R, IL33/ST2) with resulting differences between $\rho^{+}$and $\rho^{0}$ cells; iv) regulation of STAT3 transacting activity probably through both ATM-directed and ligand/receptor roots (such as IL6/IL6R) resulting in pronounced differences between $\rho^{+}$and $\rho^{0}$ cells before and after irradiation (Fig. 5D); and v) PI3K-AKT pathway (Figs. 5A and B).

ATM-dependent phosphorylation of p53 on Ser 15 and activation of ERK1/2 by MEK-dependent Thr202/Tyr204 phosphorylation were relatively similar in both $\rho^{0}$ and $\rho^{+}$HSF following $\alpha$-irradiation (Fig. 5A). However, consistent with a partial suppression of p53 activity in these cell lines by SV40 T-antigen (used for immortalization of fibroblasts), most of the downstream p53 responsive pathways were not functional before or after irradiation [40]. A strong activation of ERK $1 / 2$ was observed in both $\rho^{+}$and $\rho^{0}$ cells $4 \mathrm{~h}$ after irradiation and could be detected at decreased levels even $24 \mathrm{~h}$ after treatment (Figs. 5A and B). On the other hand, levels of active phospho-AKT (Ser473) demonstrated marginal differences between $\rho^{+}$and $\rho^{0}$ cells 4 and $24 \mathrm{~h}$ after irradiation (Figs. 5A and B). NF-kB-dependent luciferase reporter activity (reflecting a general NF- $\kappa B$-dependent transcriptional activity) increased substantially after $\alpha$-irradiation in $\rho^{+}$compared with $\rho^{0}$ cells. TNF $\alpha$ was used as the positive control for NF- $\kappa$ B activation (Fig. 5C). Because the genes of the pro-inflammatory signature could be regulated by NF-KB in concert with STAT3, we further demonstrated using STAT3-dependent luciferase activity that $\alpha$-irradiation of HSF could upregulate STAT3-transacting activity via differential regulation in $\rho^{+}$and $\rho^{0}$ cells. IL6 was used as a positive control for JAK2-STAT3 activation (Fig. 5D).

At protein level a consequence of $\alpha$-particle irradiation (24 h after exposure) was upregulation of the NF-kB/STAT3-dependent PTGS2 (COX2), a critical pro-inflammatory enzyme that was partially suppressed in $\rho^{0}$ cells compared to $\rho^{+}$cells (Fig. 5B). On the other hand, an additional increase in total DR5 levels was relatively similar in $\rho^{+}$and $\rho^{0}$ cells $24 \mathrm{~h}$ after irradiation (Fig. 5B). As we previously observed [5], ionizing radiation up-regulated surface 


\section{A}

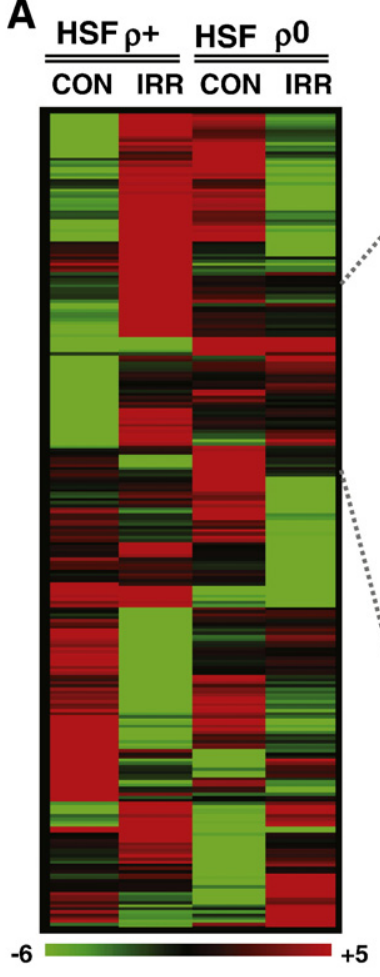

B

\begin{tabular}{|c|c|c|c|c|}
\hline \multirow[b]{2}{*}{ Biological Process } & \multicolumn{2}{|c|}{ HSF pt } & \multicolumn{2}{|c|}{ HSF p 0} \\
\hline & \begin{tabular}{|l|} 
number \\
of genes
\end{tabular} & p-value & $\begin{array}{l}\text { number } \\
\text { of genes }\end{array}$ & p-value \\
\hline $\begin{array}{l}\text { cell surface receptor linked signal } \\
\text { transduction }\end{array}$ & 15 & 0.02 & 16 & 0.0009 \\
\hline cell adhesion & 10 & 0.03 & 11 & 0.002 \\
\hline cell communication & & NS & 23 & 0.004 \\
\hline signal transduction & & NS & 22 & 0.005 \\
\hline response to stimulus & 13 & 0.02 & $\frac{22}{12}$ & 0.008 \\
\hline ion transport & & NS & 6 & 0.03 \\
\hline immune system process & 20 & 0.002 & 14 & 0.03 \\
\hline immune response & & NS & 6 & 0.03 \\
\hline developmental process & & NS & 15 & 0.03 \\
\hline cellular process & & NS & 26 & 0.04 \\
\hline cell-cell signaling & & 0.03 & 8 & 0.05 \\
\hline antigen processing and & 3 & 0.004 & & NS \\
\hline $\begin{array}{l}\text { presentation } \\
\text { cellular defense response }\end{array}$ & 5 & 0.03 & & NS \\
\hline
\end{tabular}

C

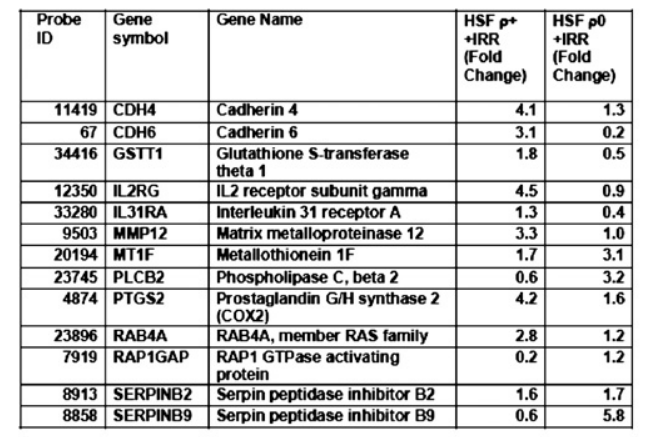

Fig. 3 - Hierarchical clustering of gene expression after alpha irradiation of HSF $\rho^{0}$ compared with HSF $\rho^{+}$. A. HSF gene expression responses at $4 \mathrm{~h}$ after irradiation with $0.5 \mathrm{~Gy}$ alpha-particles; the heatmap of differentially expressed 265 genes was made using BRB tools (http://linus.nci.nih.gov/BRB-ArrayTools.html). The inset displays a subset of the differentially expressed genes showing MMP12 and PTGS2 gene expression. The scale bar indicates induced (red) and repressed (green) expression ratios. B. Gene ontology analysis using PANTHER biological processes comparing HSF $\rho^{0}$ to $\rho^{+}$gene expression response after irradiation with 0.5 Gy $\alpha$-particles. Functionally enriched categories are shown, p-values indicate statistical significance, $p$-value cut off 0.05 and NS is not significant. C. Expression levels of selected genes in HSF $\rho^{0}$ compared with HSF $\rho^{+} 4 \mathrm{~h}$ after irradiation.

expression of TRAIL-R2/DR5 (due to increased transcription and protein trafficking) that was relatively similar in both $\rho^{+}$and $\rho^{0}$ cells $24 \mathrm{~h}$ after treatment (Fig. 5E).

Furthermore, $24 \mathrm{~h}$ after irradiation protein levels of the NF- $\kappa \mathrm{B} /$ STAT3-dependent Survivin with anti-apoptotic activity were upregulated only in $\rho^{+}$cells but not in $\rho^{0}$ cells (Fig. 5B). In contrast, basal levels of anti-apoptotic XIAP were substantially downregulated in irradiated $\rho^{+}$cells, but were low and stable in $\rho^{0}$ cells; c-FLIP (an inhibitor of caspase-8) levels were also substantially decreased in $\rho^{+}$cells and were non-detectable in $\rho^{0}$ cells 24 after irradiation (Fig. 5B). Only modest changes in Bcl-xL protein levels were detected in irradiated HSF (Fig. 5B). Furthermore, basal protein levels of Smac (DIABLO), a critical regulator of the mitochondrial apoptotic pathway, and BAX, a pro-apoptotic executor of the mitochondrial pathway, were notably decreased in $\rho^{0}$ cells compared to $\rho^{+}$cells. Smac levels were additionally decreased after irradiation of normal fibroblasts (Fig. 5B).

Taken together, these results demonstrated relatively similar changes in several signaling pathways induced by $\alpha$-irradiation in both $\rho^{0}$ and $\rho^{+}$cells, while notable changes in basal and inducible NF- $\kappa$ B and STAT activation, as well as in expression levels of their target anti-apoptotic proteins (such as PTGS2/COX2, Survivin, XIAP and CFLIP-L) suggested their role for a differential sensitization of $\rho^{0}$ versus $\rho^{+}$cells to death ligand-induced apoptosis. On the other hand, down-regulated levels of pro-apoptotic regulators, BAX and Smac, potentially could decrease levels of the mitochondria-mediated apoptosis in $\rho^{0}$ cells.

\section{Cell cycle change and levels of cell death in normal and mtDNA- depleted human fibroblasts after stress treatment}

Our next aim was to investigate general effects of deficiency of mitochondrial function on cell cycle and cell survival after $\alpha$-irradiation, including the regulation of both the mitochondrial and the death receptor-mediated apoptotic pathways. Exposure to ionizing radiation ( $0.5 \mathrm{~Gy}, \alpha$-particles) induced pronounced G2/M arrest in HSF (Fig. 6A). This effect was substantially increased in $\rho^{0}$ cells (a ratio of cell populations at G2/M versus G1 phase increased from 0.7 to 2.1), probably based on numerous changes in the cellcycle regulatory proteins, such as p21-Cip1 (encoding by CDKN1A) (Figs. 4A and 6B) and E2F3 transcription factor (encoding by E2F3), which showed increased basal expression in mtDNA-depleted 
A

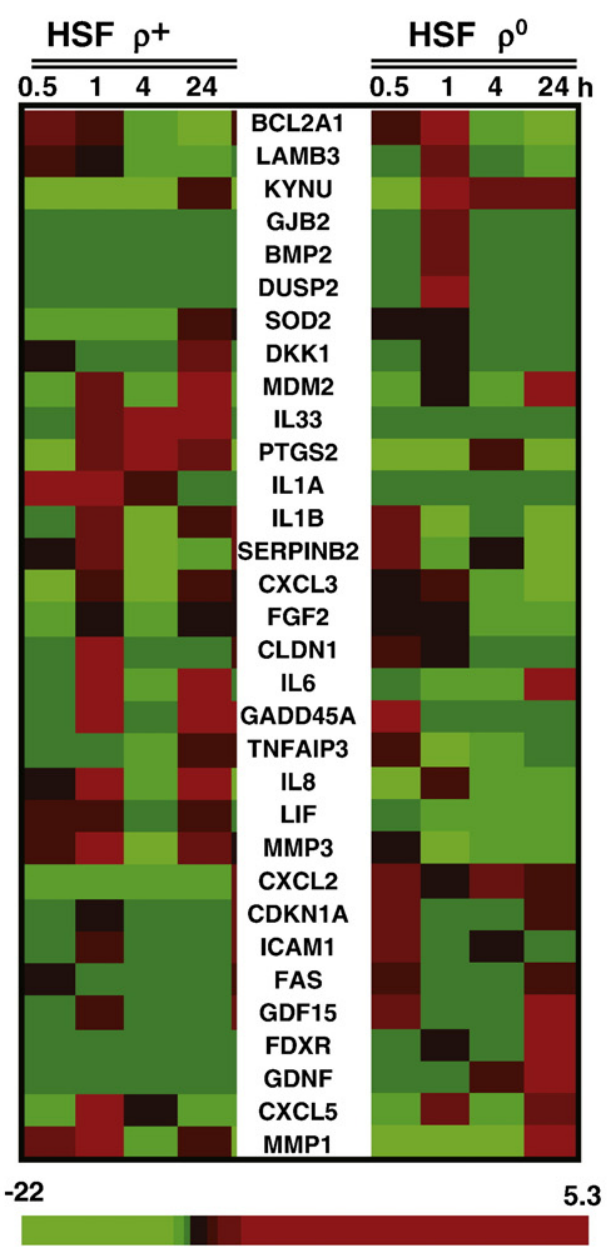

C

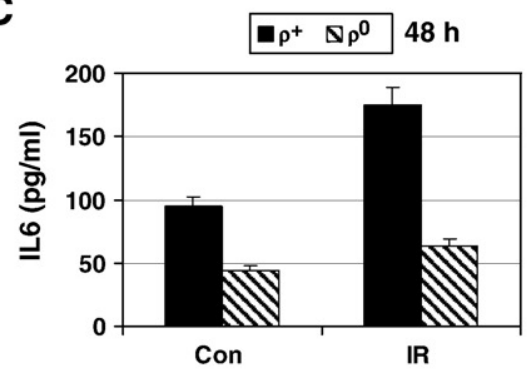

B

NF-KB-dependent gene expression
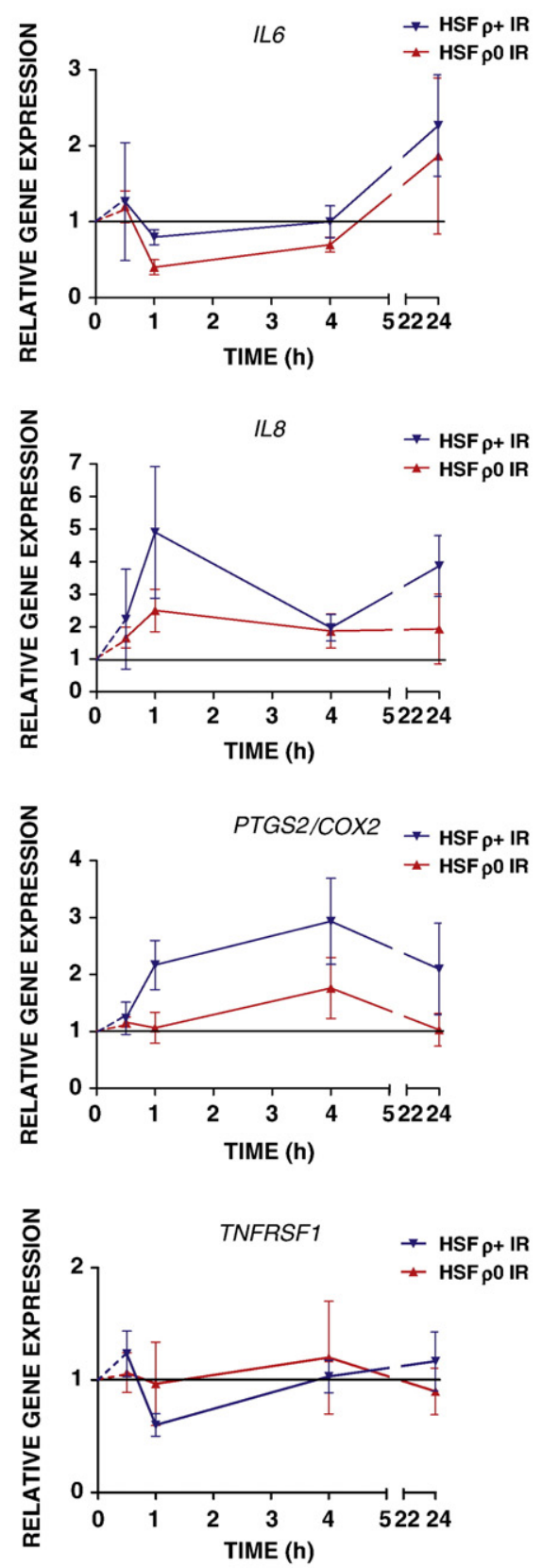

Fig. 4 - Validation of differential gene expression in mtDNA-depleted human skin fibroblasts, (HSF $\left.\rho^{0}\right)$, and their parental cells (HSF $\rho^{+}$) after $\alpha$-irradiation using qRT-PCR. A. Heatmap of gene expression levels in the low density array panel. Gene expression was determined by quantitative real time PCR (qRT-PCR). 33 genes were analyzed across the time course of $0.5,1,4$ and $24 \mathrm{~h}$ in non-treated and $\alpha$-irradiated ( $0.5 \mathrm{~Gy}$ ) cells. Heatmap for up-regulated and down-regulated genes was generated using BRB Array-Tools software. B. Relative gene expression changes in IL6, IL8, PTGS2/COX2 and TNFRSF1 in HSF in the time course. Gene expression was determined qRT-PCR. Points are the mean of three independent replicates. C. Relative increase in IL6 secretion in $\rho^{+}$and $\rho^{0} \mathrm{HSF} \mathbf{4 8} \mathrm{h}$ after exposure to ionizing irradiation (0.5 Gy).

cells (Table 2). No notable apoptosis was detected $24-48 \mathrm{~h}$ after exposure of skin fibroblasts to $\alpha$-radiation $(0.5 \mathrm{~Gy})$ (Fig. 6A). Clonogenic survival assay demonstrated modest decrease in survival of $\rho^{0}$ cells compared to $\rho^{+}$cells reflecting slow death of irradiated cells using non-apoptotic mechanisms 12 days after irradiation (Fig. 6B).
On the other hand, changes in levels of Smac (DIABLO) and BAX (Fig. 5B) could differentially sensitize mitDNA-deficient HSF and normal HSF to apoptosis via the mitochondrial pathway. Indeed, a combination of $\alpha$-irradiation (0.5 Gy) and LY294002 (a PI3K-AKT inhibitor) or sodium arsenite and LY294002 induced cell death that could be substantially reduced by LEHD [N-acetyl-Leu-Glu-His-Asp- 
A

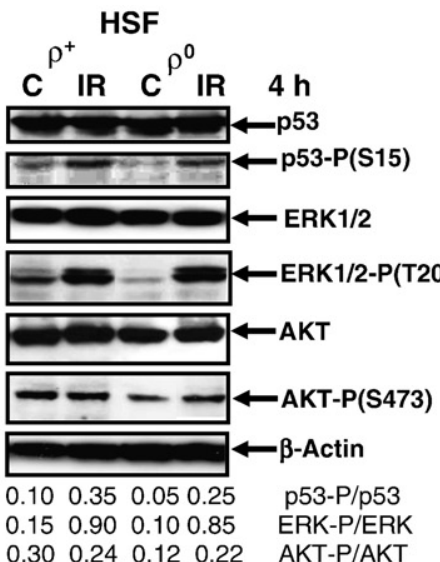

B

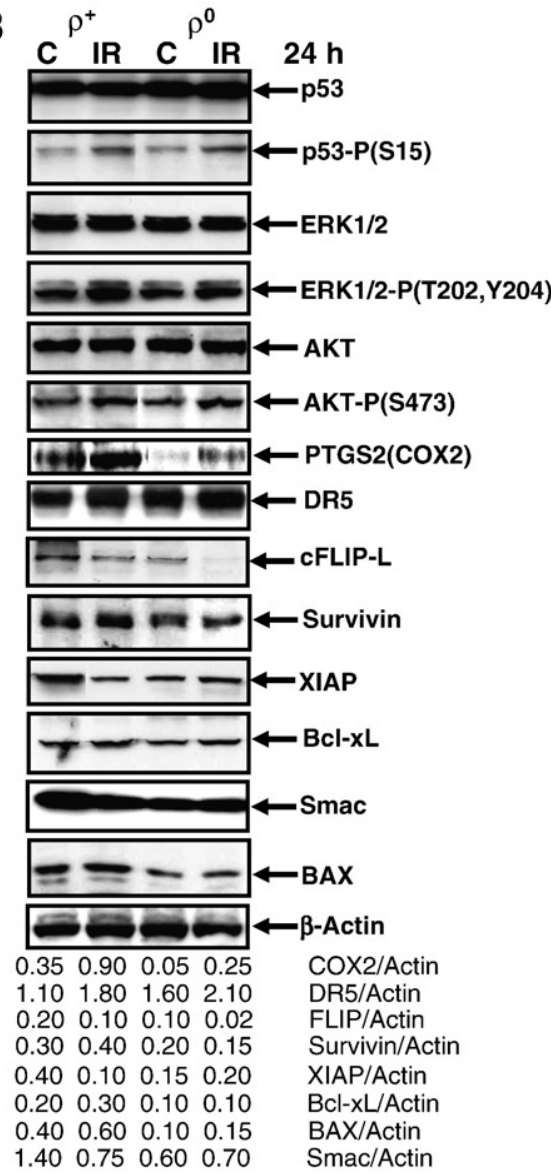

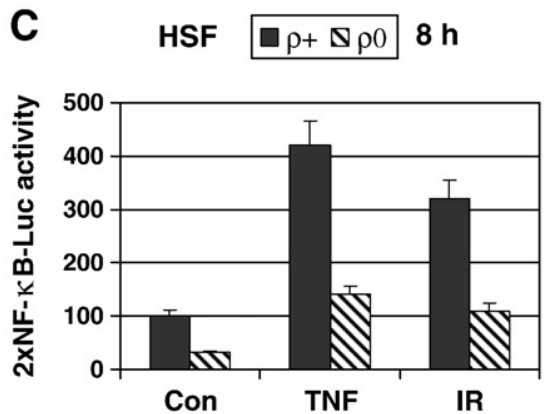

D $\quad \square+\mathbf{s} \rho 0 \mathbf{8 h}$

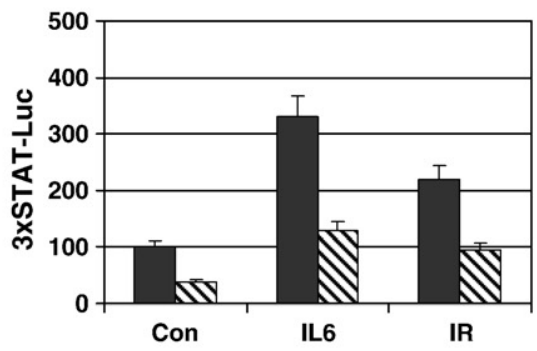

E
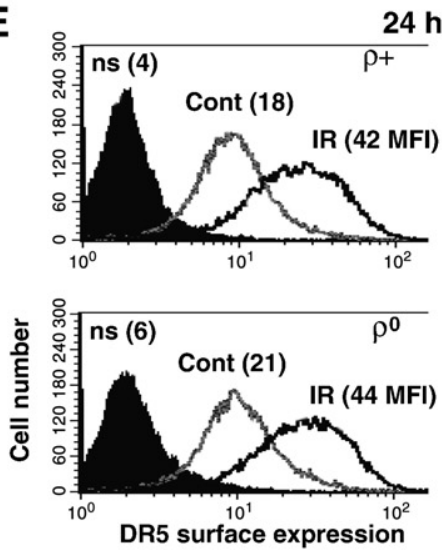

Fig. 5 - Activation of the main signaling pathways and levels of target proteins after $\alpha$-irradiation of HSF. A, B. Western blot analysis of indicated proteins $4 \mathrm{~h}$ and $24 \mathrm{~h}$ after $\alpha$-irradiation $(0.5 \mathrm{~Gy})$ of $\rho^{+}$and $\rho^{0} \mathrm{HSF}$. C. NF- $\mathrm{kB}$-dependent luciferase reporter activity (2xNF-KB-Luc) was determined in transiently transfected $\rho^{+}$and $\rho^{0}$ HSF before and $8 \mathrm{~h}$ after $\alpha$-irradiation (0.5 Gy) or $8 \mathrm{~h}$ after TNF $\alpha$ $(20 \mathrm{ng} / \mathrm{ml})$ treatment. D. STAT-dependent luciferase reporter activity (3xSTAT-Luc) was determined in transiently transfected $\rho^{+}$ and $\rho^{0}$ HSF before and $8 \mathrm{~h}$ after $\alpha$-irradiation $(0.5 \mathrm{~Gy})$ or $8 \mathrm{~h}$ after IL6 (10 ng/ml) treatment. Error bars represent mean \pm S.D.

(Student's $\boldsymbol{t}$ test, $\boldsymbol{p}<\mathbf{0 . 0 5}$ ). E. Surface expression of TRAIL-R2/DR5 in HSF before and $24 \mathrm{~h}$ after $\alpha$-irradiation was determined using immunostaining and FACS analysis.

CHO (aldehyde)], a caspase-9 inhibitor, but less efficiently by IETD [Nacetyl-Ile-Glu-Thr-Asp-CHO (aldehyde)], a caspase-8 inhibitor in normal HSF (Fig. 6D), indicating that caspase-9-dependent mitochondrial pathway was involved in the execution of cell death following these treatments. As expected, caspase-9-dependent apoptotic pathway was substantially downregulated in $\rho^{0}$ cells (Fig. 6D).
Surface receptor levels and death-ligand induced apoptosis in normal and mtDNA-depleted human fibroblasts

As we already demonstrated, both $\rho^{0}$ and $\rho^{+}$HSF exhibited TRAILR2/DR5 surface expression at the similar levels, while surface TRAIL-R1/DR4 was not detectable (Figs. 5E and 7A). TRAIL alone 
A

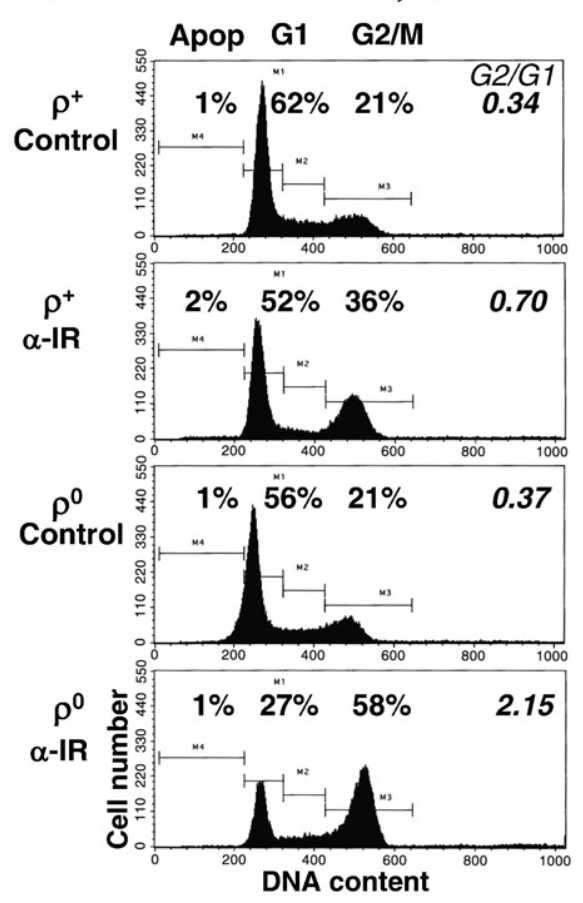

B

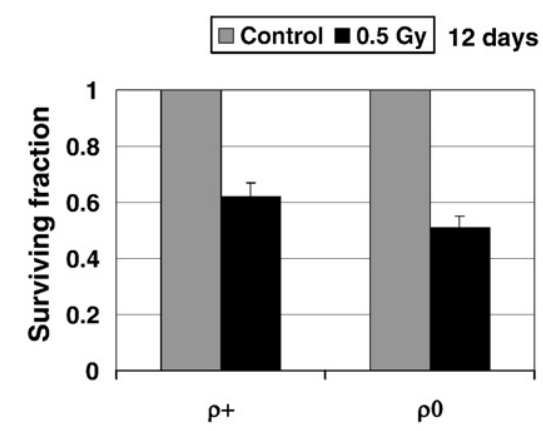

C

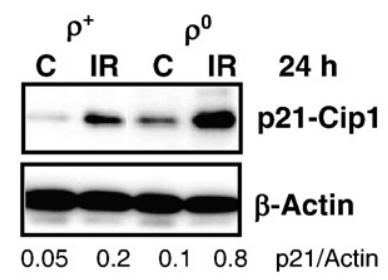

D

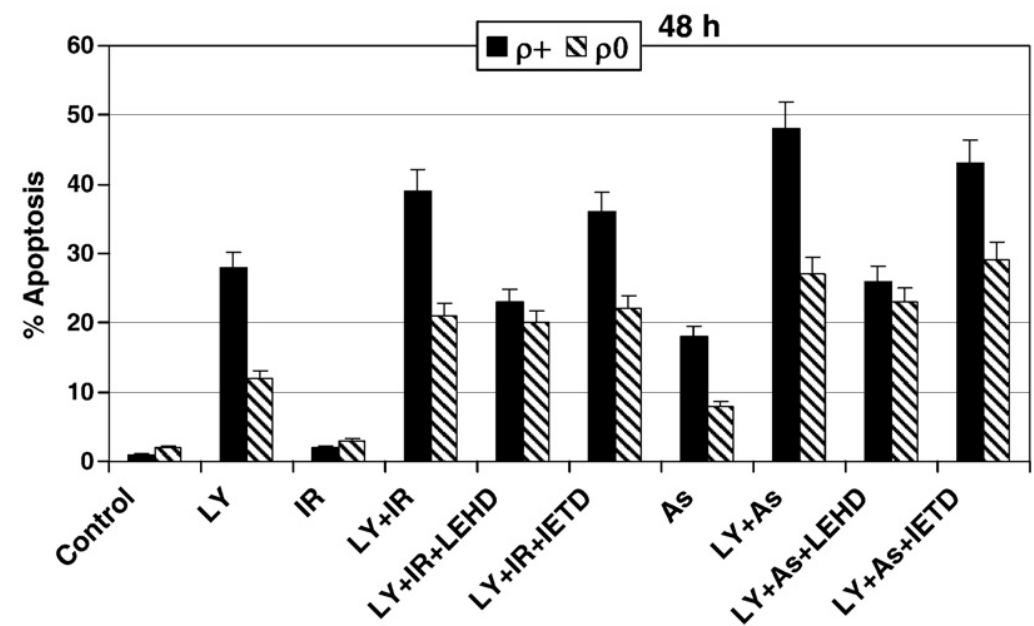

Fig. 6 - Cell cycle and apoptotic analysis of mtDNA-depleted human skin fibroblasts (HSF $\rho^{0}$ ) and their parental cells (HSF $\rho^{+}$). A. Cell cycle analysis of $\rho^{+}$and $\rho^{0}$ HSF after $\alpha$-irradiation $(0.5 \mathrm{~Gy})$ was performed using PI staining of DNA and FACS analysis. B. Clonogenic survival fraction (SF) of control and treated cells 12 days after irradiation. C. Western blot analysis of indicated proteins $24 \mathrm{~h}$ after $\alpha-$ irradiation ( $0.5 \mathrm{~Gy})$ of $\rho^{+}$and $\rho^{0}$ HSF. D. Apoptosis was induced by $\alpha$-irradiation $(0.5 \mathrm{~Gy})$ alone or in combination with LY294002 $(50 \mu \mathrm{M})$, sodium arsenite (As, $4 \mu \mathrm{M})$ alone or in combination with LY294002 (50 $\mu \mathrm{M})$, in the presence or the absence of caspase inhibitors, IETD or LEHD $(50 \mu \mathrm{M})$, in $\rho^{+}$and $\rho^{0}$ HSF.

was only a modest inducer of apoptosis in HSF. However, $\rho^{0}$ and $\rho^{+}$ HSF demonstrated different apoptotic response after treatment with TRAIL in the presence of cycloheximide (CHX), an inhibitor of protein synthesis and a classical accelerator of Fas-, TNFR- and TRAIL-R-mediated apoptosis. Surprisingly, TRAIL + CHX induced apoptotic levels were substantially higher in $\rho^{0}$ cells compared to $\rho^{+}$cells (Fig. 7B).

The basal levels of surface FAS and IL6R $\alpha$, both receptor proteins are known as NF- $\kappa \mathrm{B}$ transcriptional targets, were decreased in $\rho^{0}$ cells. Nerve growth factor receptor (NGFR1-p75/ TNFRSF16) surface expression was actually induced in mtDNA- depleted HSF (Fig. 7A), although a role for such change was still not established. Only modest alteration of FasL $+\mathrm{CHX}$ induced apoptosis was observed in mtDNA-depleted HSF, compared to control cells (Fig. 7B), probably due to the simultaneous decrease in Fas surface levels and the NF- $\kappa \mathrm{B}-$ dependent anti-apoptotic protection in $\rho^{0}$ cells. TNF $\alpha$ and CHX induced only marginal levels of apoptosis in HSF. NGF alone or in concert with CHX did not initiate pronounced apoptosis in HSF (Fig.7B).

An additional analysis of TRAIL + CHX induced apoptosis demonstrated dose-dependent effects of TRAIL with substantially increased levels of apoptosis in $\rho^{0}$ cells (Fig. 8A). Pretreatment 
A
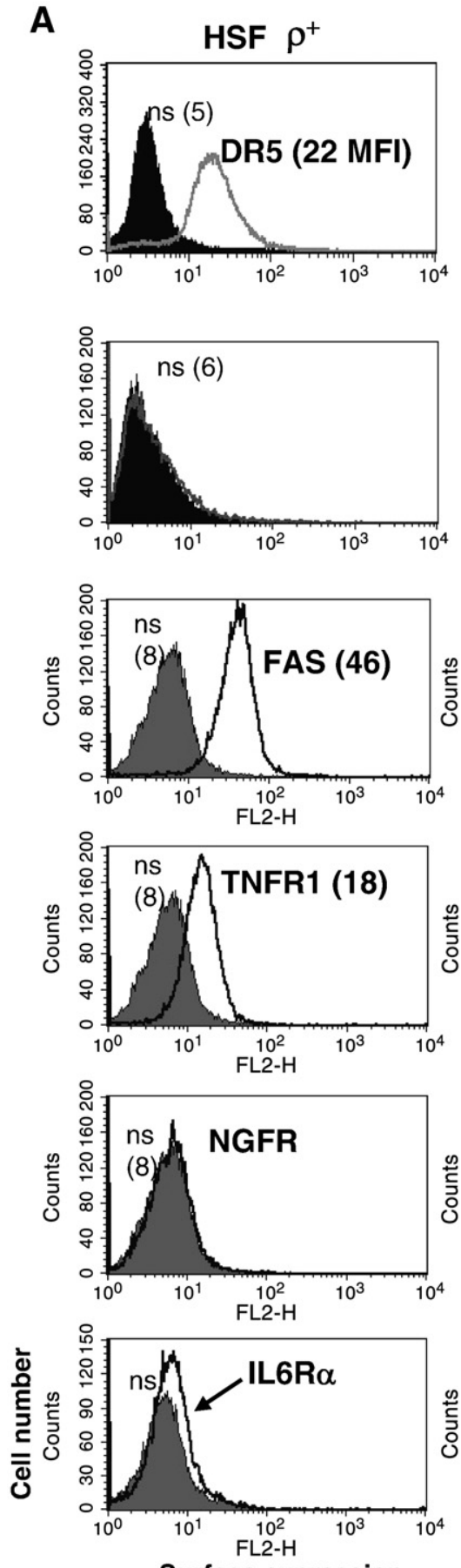

Surface expression
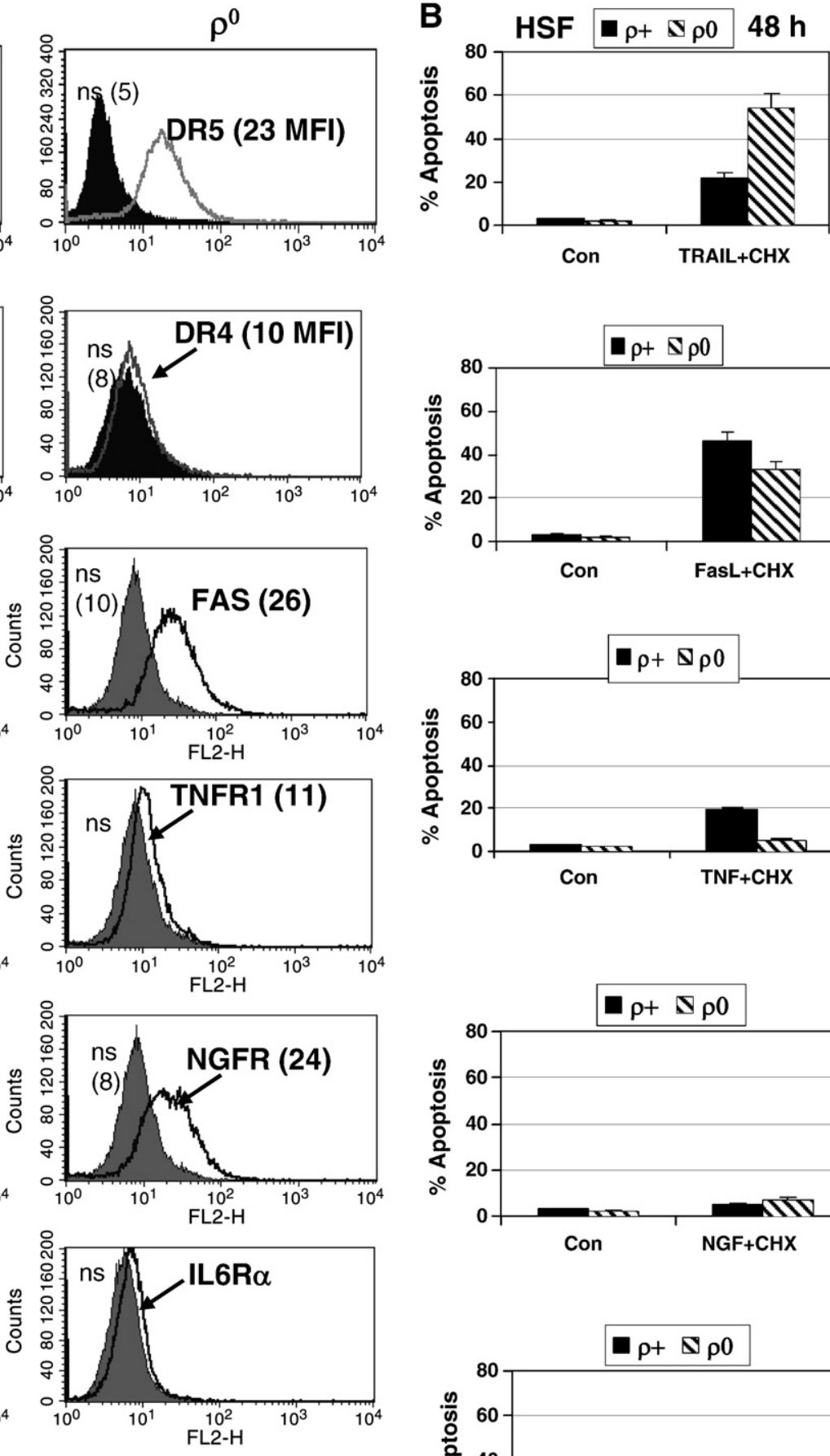

Fig. 7 - Surface expression of receptors and death ligand/receptor-induced apoptosis in HSF. A. Surface expression of TRAIL-R2/DR5, TRAIL-R1/DR4, FAS, TNFR1, NGFR1 and IL6R $\alpha$ was determined using immunostaining with the corresponding PE-labeled mAbs and the subsequent FACS analysis of $\rho^{+}$and $\rho^{0}$ HSF. Medium fluorescent intensity (MFI) is indicated in brackets. B. Induction of apoptosis by ligands, FasL ( $25 \mathrm{ng} / \mathrm{ml})$, TNF $\alpha(20 \mathrm{ng} / \mathrm{ml})$ and NGF $(50 \mathrm{ng} / \mathrm{ml})$ in the presence CHX $(1 \mu \mathrm{g} / \mathrm{ml})$.

with $\alpha$-radiation $(0.5 \mathrm{~Gy})$ further increased levels of TRAIL and CHX induced apoptosis in both $\rho^{0}$ and $\rho^{+}$cells (Fig. 8B), due to radiation-induced upregulation of surface expression of TRAIL-R2/ DR5 [5], which was observed in both $\rho^{0}$ and $\rho^{+}$cells (Fig. 5E), and a
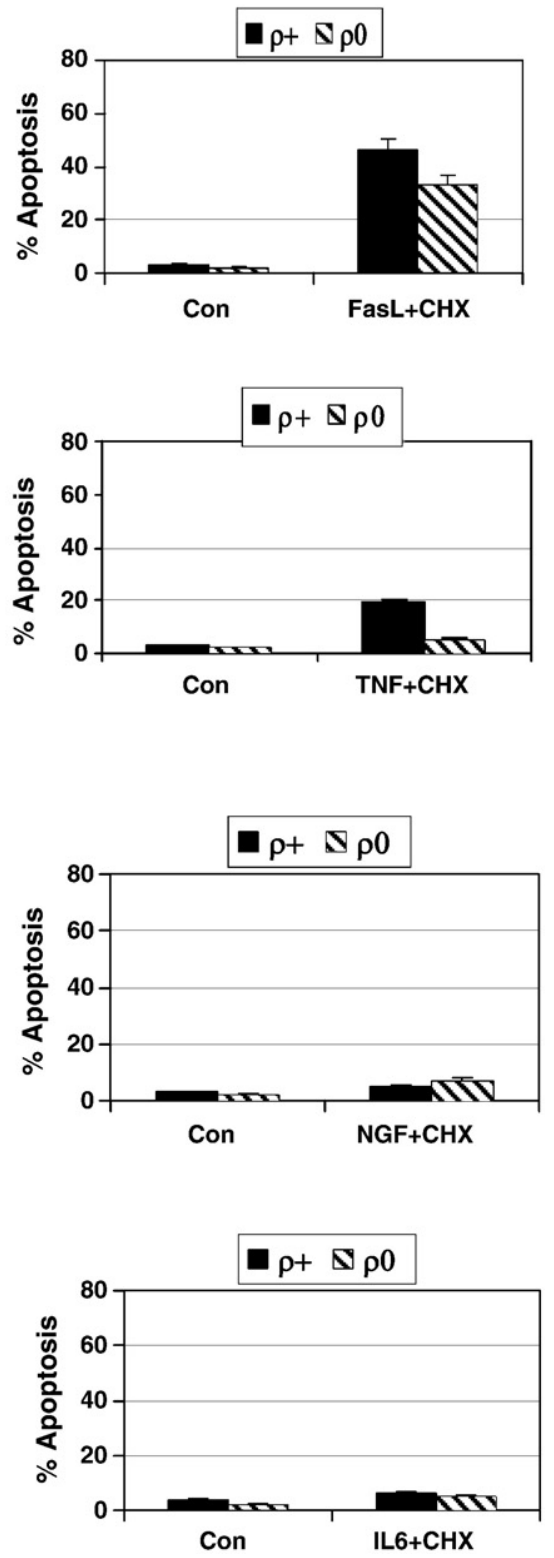

partial down-regulation of cell anti-apoptotic functions. TRAIL + CHX induced apoptosis was significantly blocked by IETD (caspase- 8 inhibitor), but less efficiently by LEHD (caspase- 9 inhibitor) (Fig. 8B). 
A

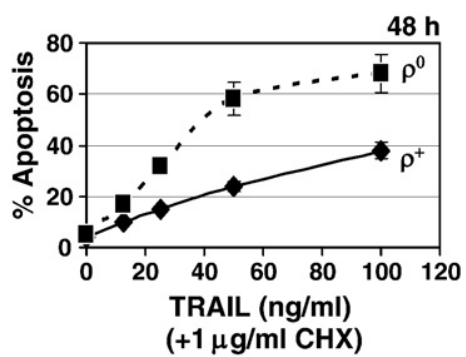

B

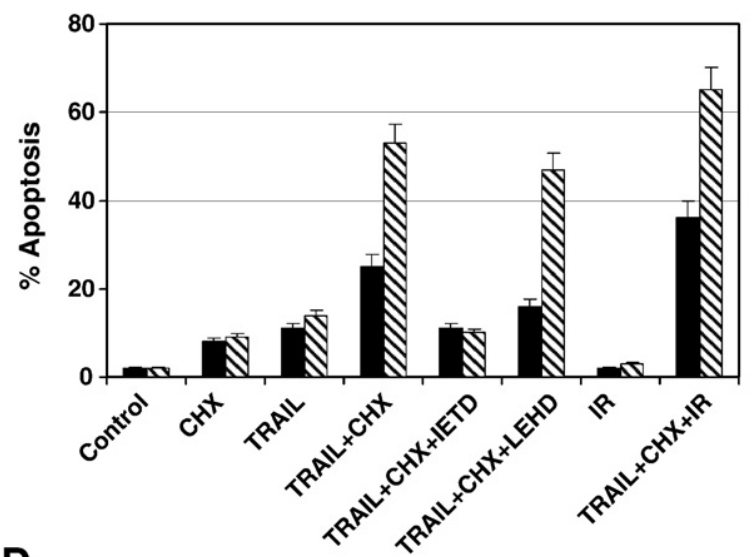

D.

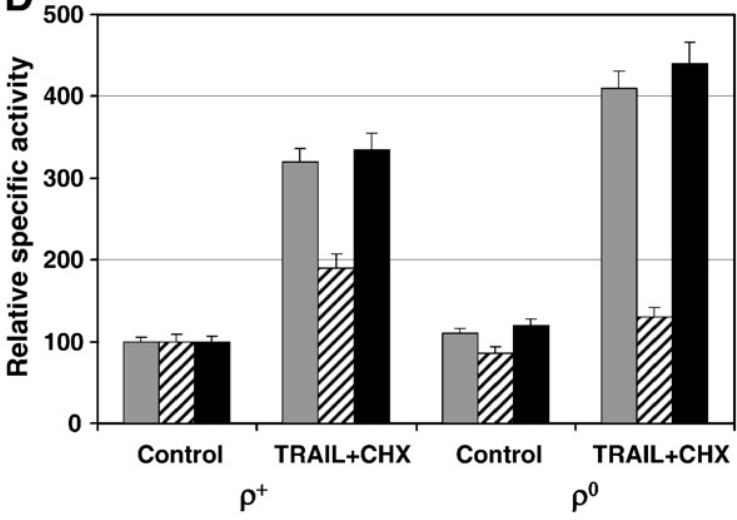

C
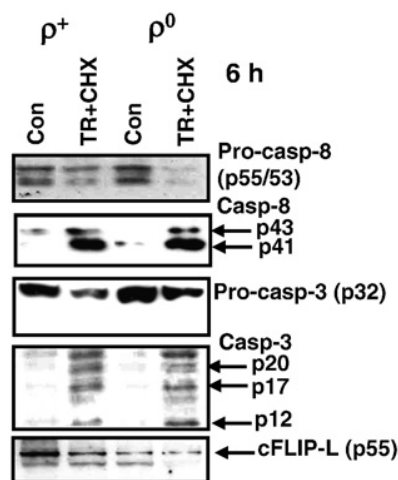
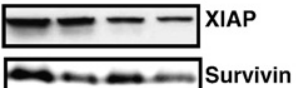

Survivin

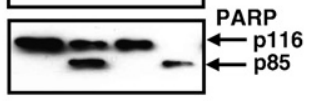

$\beta$-Actin

Fig. 8 - TRAIL and CHX induced apoptosis in HSF. A. Dose-dependent response of $\rho^{+}$and $\rho^{0}$ HSF to TRAIL (10-100 ng/ml) in the presence of cycloheximide (CHX, $1 \mu \mathrm{g} / \mathrm{ml}$ ). Apoptotic levels (\% cells in pre-G1/G0) were determined $48 \mathrm{~h}$ after treatment using PI staining and FACS analysis. Error bars represent mean \pm S.D. (Student's $t$ test, $p<0.05$ ). B. Apoptosis induced by TRAIL (50 ng/ml) and CHX $(1 \mu \mathrm{g} / \mathrm{ml})$ in the presence or the absence of IETD or LEHD $(50 \mu \mathrm{M})$ in $\rho^{+}$and $\rho^{0}$ HSF. An additional effect of $\alpha$-irradiation (IR at $0.5 \mathrm{~Gy}$ ) on (TRAIL + CHX)-induced apoptosis was also determined. Apoptotic levels (\% cells in pre-G1/G0) were determined 48 h after treatment using PI staining and FACS analysis. Error bars represent mean \pm S.D. (Student's $t$ test, $p<0.05$ ). C. Western blot analysis of caspase-8-dependent pathway following TRAIL + CHX treatment of HSF. Decreased levels of procaspase-8 (determined with mAb to p55) reflect its cleavage and activation. The subsequent activation of caspase- 3 results in PARP cleavage that was more advanced in $\rho^{0}$ HSF. D. Relative specific activity of caspase-8, caspase- 9 and caspase- 3 in total cell extracts of $\rho^{+}$and $\rho^{0}$ HSF 6 h after TRAIL + CHX treatment.

TRAIL + CHX treatment after $6 \mathrm{~h}$ induced relatively similar cleavage of procaspase- 8 and procaspase- 3 in HSF, which was somewhat more pronounced in $\rho^{0}$ cells. The basal anti-apoptotic activity of cFLIP-L (an inhibitor of caspase-8), XIAP and Survivin (inhibitors of the executive caspases) was finally involved in modulation of caspase-3 enzymatic activity, resulting in its increase in $\rho^{0}$ cells that was well detected using caspase- 3 classical target PARP (Fig. 8C). Furthermore, direct determination of enzymatic activities of caspase-8, caspase-9 and caspase-3 in total cell lysates demonstrated upregulated levels of caspase8 and, especially caspase- 3 activity in $\rho^{0}$ cells compared to $\rho^{+}$cells $6 \mathrm{~h}$ after treatment of cells with TRAIL + CHX. Caspase- 9 activity was increased in $\rho^{+}$but not in $\rho^{0}$ cells (Fig. 8D).

Taken together, these results demonstrated that depletion of mtDNA (accompanied by inhibition of mitochondrial function) caused a substantial downregulation of activation of the 
A

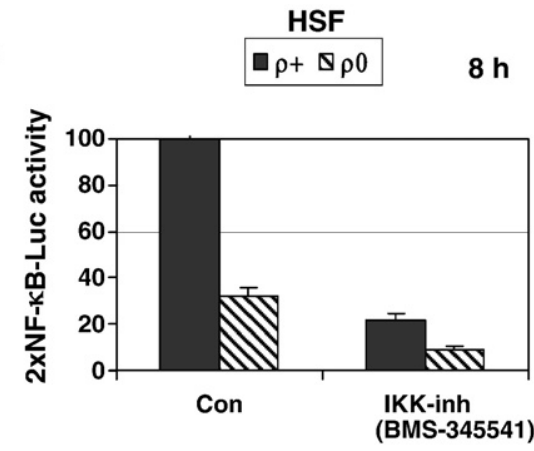

B

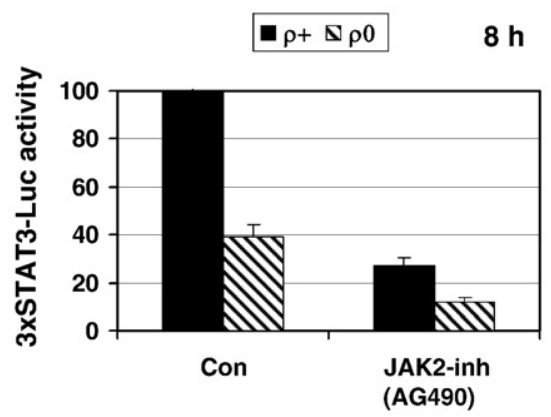

E

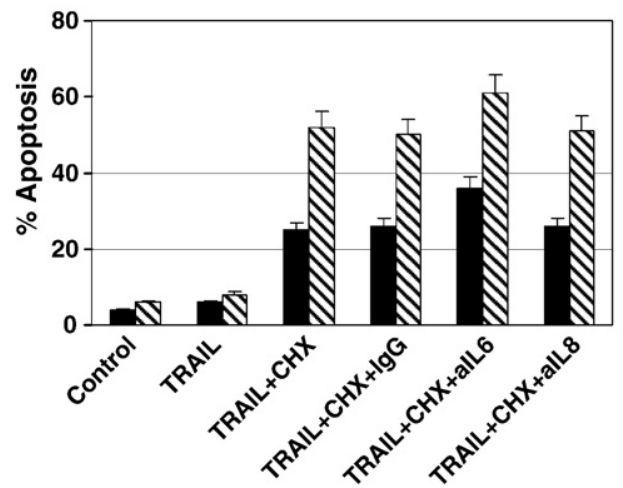

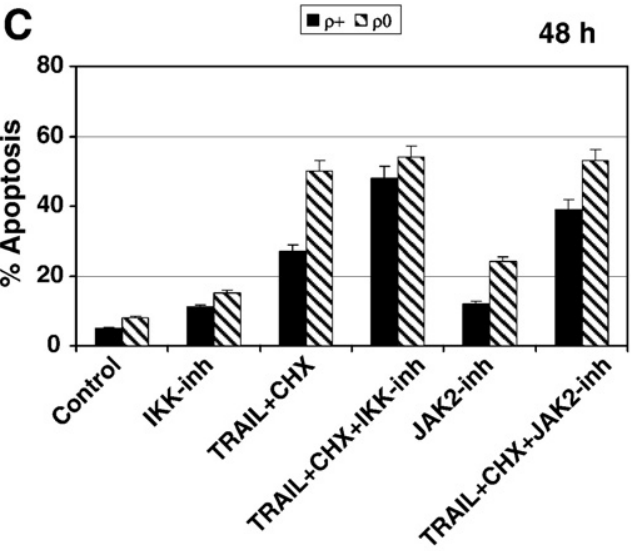

D

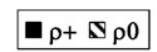

$48 \mathrm{~h}$

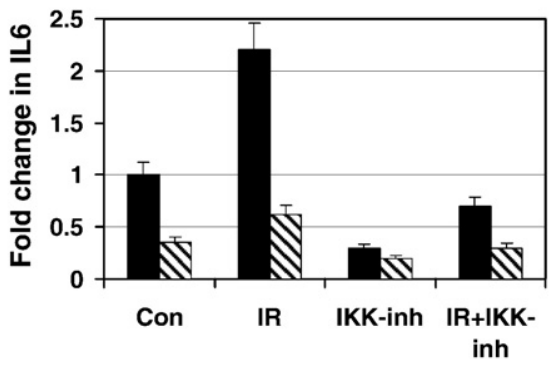

(IR) $48 \mathrm{~h}$

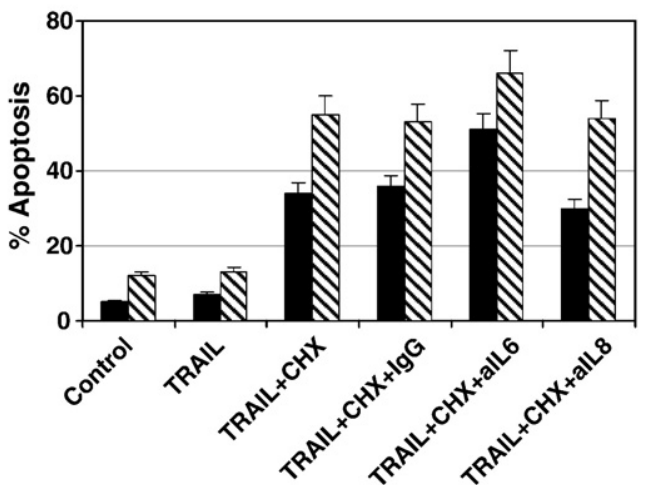

Fig. 9 - Modulation of TRAIL-induced apoptosis in HSF using inhibitory mAbs and low molecular inhibitors of cell signaling pathways. A, B. Effects of suppression of IKK $\beta-N F-\kappa B$ by BMS-345541 (10 $\mu \mathrm{M})$ and JAK2-STAT3 by AG490 (50 $\mu$ M) on 2 xNF-KB-Luc and 3xSTAT3-Luc reporter activities, respectively, in transiently transfected HSF. C. Effects of suppression of IKIK $\beta-N F-\kappa B$ by BMS-345541 (10 $\mu \mathrm{M})$ and JAK2-STAT3 by AG490 (50 $\mu \mathrm{M})$ on TRAIL-induced apoptosis. Apoptotic levels (\% cells in pre-G1/G0) were determined $48 \mathrm{~h}$ after treatment using PI staining and FACS analysis. Error bars represent mean \pm S.D. (Student's $t$ test, $p<0.05$ ). D. Effect of IKK $\beta-N F-\kappa B$ inhibitor, BMS-345541 (10 $\mu \mathrm{M})$, on relative increase in IL6 secretion in $\rho^{+}$and $\rho^{0}$ HSF 48 h after exposure to ionizing irradiation. E. Effects of blockage of IL6- or IL8-dependent signaling with anti-IL6 mAb (5 $\mathrm{mg} / \mathrm{ml})$ or anti-IL8 $\mathrm{mAb}(5 \mu \mathrm{g} / \mathrm{ml})$, respectively, added into the cell media on TRAIL-induced apoptosis in $\rho^{+}$and $\rho^{0}$ HSF. Cells were additionally pretreated with 0.5 Gy $\alpha$-irradiation (the right panel). Error bars represent mean \pm S.D. (Student's $t$ test, $p<0.05$ ).

mitochondrial apoptotic pathway (Fig. 6D). However, this depletion simultaneously upregulated levels of activation of the exogenous TRAIL-Receptor-mediated pathway (Fig. 8), probably due to a partial suppression of anti-apoptotic functions in $\rho^{0}$ cells.

Expression levels of many NF- $\kappa \mathrm{B}-$ dependent target genes were downregulated in mtDNA-depleted cells. The initiation of cell signaling cascades that activate IKK-NF-KB could be a result of several types of ligand/receptor interactions. TNF $\alpha / T N F R 1$ interaction is known to be one of the major inducers of the IKK-NF- $\kappa B$ pathway [41]. Decreased TNF-R1 surface expression could further downregulate NF-KB-driven transcription induced by exogenous TNF $\alpha$ in mtDNA-depleted cells (Fig. 7A). Based on very low levels of expression determined by qRT-PCR and ELISA, endogenous TNF $\alpha$ was not probably the main inducer of NF-KB in skin fibroblasts, suggesting 
that a different ligand-receptor interaction (such as IL13/IL1R, IL33/ ST2, FasL/FAS, TRAIL/DR5) might initiate the NF-kB signaling pathway in HSF via autocrine/paracrine mechanisms. As we already mentioned, IL1 $\beta$ secretion by normal HSF increased almost 2-fold $24 \mathrm{~h}$ after irradiation, while $\rho^{0}$ cells did not demonstrate upregulation of IL1 $\beta$ secretion.

Based on numerous investigations of a role for NF-kB in both cell survival and cell death regulatory pathways [42], we further elucidated the significance of this transcription factor for regulation of TRAIL-mediated apoptosis in HSF, suggesting that pharmacological inhibition of NF- $\kappa \mathrm{B}$ activity in $\rho^{+}$cells would increase TRAIL-mediated apoptosis in these cells close to levels observed in mtDNA-depleted cells (with decreased NF-KB activity).

\section{Suppression of IKK $\beta-N F-\kappa B$ and JAK2-STAT3 activities and upregulation of TRAIL-induced apoptosis in HSF}

Both IKKß-NF-KB and JAK2-STAT3 pathways are involved in the regulation of cell proliferation, cell survival and death. Several cytokines (including IL6), which are NF- $\kappa B$ transcriptional targets, further activate the JAK2-STAT3 pathway by paracrine/autocrine mechanisms [43]. To provide evidence that downregulation of critical NF- $\kappa B$ gene targets was responsible for upregulation of TRAIL-induced apoptosis in $\rho^{0}$ cells, we suppressed activity of the IKK-NF- $\kappa B$ pathway by IKK $\beta$ inhibitor BMS-345541 (10 $\mu \mathrm{M})$ that resulted in the general suppression of NF- $\mathrm{KB}$-driven transcription in HSF (Fig. 9A). Furthermore, we used AG490 (50 $\mu \mathrm{M})$, a JAK2STAT3 inhibitor, to evaluate the effect of suppression of the STAT3 signaling pathway in regulation of TRAIL-induced apoptosis (Fig. 9B). Both IKK $\beta-N F-\kappa B$ inhibitor and JAK2-STAT3 inhibitor substantially increased levels of TRAIL and CHX induced apoptosis of $\rho^{+}$HSF (Fig. 9C). Hence, active NF-kB and STAT3 caused suppression of TRAIL + CHX induced apoptosis in $\rho^{+}$cells, which almost achieved the levels observed in $\rho^{0}$ cells when NF- $\kappa$ B was inhibited in $\rho^{+}$cells.

HSF actively express and produce IL6. Radiation induced activation of NF-KB pathway upregulated expression of IL6 gene followed by increased IL6 secretion into the media. This was less pronounced in mtDNA-depleted cells; furthermore, IKK-NF- $k B$ inhibitor substantially blocked IL6 secretion in normal HSF before and after irradiation (Fig. 9D). Inhibitory monoclonal antibodies (mAbs) against IL6 and IL8 were added to the cell media blocking autocrine and paracrine signal transmission in HSF that was potentially linked with the downstream activation of STAT3. Anti-IL6, but not anti-IL8 mAb increased levels of TRAIL and CHX induced apoptosis in both $\rho^{+}$and $\rho^{0}$ HSF, especially after $\alpha$-irradiation, further demonstrating protective effects of IL6 against TRAIL-mediated apoptosis (Fig. 9E). However, IL6-dependent signaling pathway with the downstream activation of STAT3 was not the only critical anti-apoptotic regulator in HSF, since suppression of IL6 signaling pathway by inhibitory $\mathrm{mAb}$ did not result in similar levels of TRAIL + CHX induced apoptosis for both $\rho^{+}$and $\rho^{0} \mathrm{HSF}$ (Fig. 9E).

A role of IL33, an alternative inducer of the NF- $k B$ signaling pathway was recently described for signal transduction in HSF. Accordingly, anti-IL33 mAb also additionally increased TRAILmediated apoptosis of HSF [44]. Taken together, our data confirmed a role of the IKK $3-\mathrm{NF}-\kappa \mathrm{B}$ and JAK2-STAT3 pathways in protection from TRAIL + CHX induced apoptosis in HSF and indicated that a partial suppression of these pathways in mtDNAdepleted cells might be responsible for upregulation of TRAILinduced apoptosis.

\section{Regulation of TRAIL-induced apoptosis in mtDNA-depleted SAEC}

To further confirm upregulation of TRAIL and CHX induced apoptosis in mtDNA-depleted cells, we used the second system of mtDNAdepleted cells that was established from human small airway epithelial cells (SAEC) immortalized by hTERT (Suppl. Fig. 1A), as a result of a prolonged treatment of SAEC by ethidium bromide. Creation of this cell system was substantially more difficult task compared to HSF, due to probably a recently described phenomenon of strong positive effect of telomerase activity on normal mitochondrial function [45]. As expected, mtDNA-depleted SAEC had suppressed cytochrome-c oxidase activity (Suppl. Fig. 1B), strongly downregulated mitochondrial membrane potential (Suppl. Fig. 1B) and profoundly decreased levels of oxygen consumption (Suppl. Fig. 1C). Both $\rho^{0}$ cells and the parental $\rho^{+}$SAEC demonstrated negligible levels of DR4 and intermediate surface levels of DR5 (Suppl. Fig. 2A). Similarly with the HSF system, $\rho^{0}$ SAEC showed decreased apoptosis levels induced through the mitochondrial pathway with a combination of sodium arsenite and LY294002 (Suppl. Fig. 2B). However, upregulation of levels of TRAIL + CHX induced apoptosis was observed in $\rho^{0}$ SAEC (Suppl. Fig. 2B). Pretreatment with IKK $\beta$ inhibitor, BMS-345541 $(10 \mu \mathrm{M})$, further increased levels of TRAIL + CHX induced apoptosis in $\rho^{+}$SAEC that almost achieved levels in $\rho^{0}$ SAEC (Suppl. Fig. 2C). An inhibitory antibody against IL6 also increased levels of TRAIL and CHX induced apoptosis in $\rho^{+}$SAEC (Suppl. Fig. 2D). Collectively, these data confirmed a protective role of IKK $3-\mathrm{NF}-\kappa \mathrm{B}$, as well as NF- $\kappa \mathrm{B}$ dependent IL6 signaling against TRAIL and CHX induced apoptosis and demonstrated a partial loss of the NF- $\kappa \mathrm{B}$-dependent protective function in mtDNA-depleted SAEC.

\section{Discussion}

The delivery of energy by oxidative phosphorylation [46] and execution of cell death by apoptosis [47] are crucial functions of mitochondria, the disturbance of which could be involved in the initiation and progression of human pathology. Comprehensive gene analysis of mtDNA-depleted cells that was performed in the present study convincingly demonstrated a substantial contribution of mitochondria in the regulation of expression of proinflammatory signature genes, IL6, IL17B, IL18, IL19, IL28B, IL1R1, IL21R and IL31RA, which were decreased after mitochondrial DNA depletion. A recent publication of Zhou et al. [48] further confirmed a direct connection between mitochondrial function and the inflammasome activation.

The proper and efficient function of the mitochondrial death pathway, which is activated by different types of stress, requires high levels of ATP [9]. The common strategy of cancer genomes during cancer progression driven by Darwinian selection is to substitute oxidative phosphorylation by oxidative glycolysis with strongly decreased production of ATP $[9,49]$. This can be achieved by different approaches, such as mitochondrial mutagenesis affecting key enzymes of the oxidative phosphorylation or general mitochondrial DNA depletion [50]. Alternatively, induction of HIF-1 expression that stimulated key steps of glycolysis and inhibited the Krebs cycle resulted in suppression of mitochondrial function [13,51]. Together with upregulation of anti-apoptotic proteins of the Bcl2 family, the inhibition of mitochondrial respiration results in suppression of the 
activity of the mitochondrial death pathway in most human carcinomas, undoubtedly demonstrating the selective advantage of cancer clones with suppressed mitochondrial function.

Consequently, one of the critical problems for cancer treatment is whether alternative death receptor-mediated apoptotic pathways remain active or could be reactivated in cancer cells with partially or almost completely suppressed mitochondrial function and a deficiency of ATP. It is necessary to highlight that at normal energy conditions in cells, the mitochondrial and the deathreceptor mediated pathway could tightly collaborate with additional amplification of effects for receptor-mediated apoptosis. It takes place through the mitochondrial route based on caspase8 mediated processing of Bid followed by $\mathrm{tBid}, \mathrm{BAX}, \mathrm{BAK}$ and $\mathrm{Bcl}-2 /$ $\mathrm{Bcl}-\mathrm{xL}$ interaction and mitochondrial outer membrane permeabilization $[2,8]$. However, the suppression of the mitochondrial pathway during cancer development does not automatically turn off the death-receptor pathway. Paracrine and autocrine cytokine and growth factor signaling that dramatically increases during cancer progression could additionally increase survival functions in cancer cells through blockage of the death receptor mediated pathways based on the NF- $\mathrm{BB}$ and STAT3 signaling, which appears to play the leading role for regulation of cancer cell proliferation and survival [43].

To address the problem of activity of TRAIL-Receptor mediated pathway for induction of apoptosis in the case of suppression of mitochondrial functions, we used in the present study a well established, but simplified model system of mtDNA-depleted $\rho^{0}$ cells [14]. Multiple roles of NF-KB and STAT3 in the positive and the negative regulation of apoptotic pathways have been a subject of numerous investigations [52-54]. In general, IKK-NF-кB-IL6JAK2-STAT3 signaling pathway is involved in anti-apoptotic protection of normal and cancer cells [55-57]. Mutual cross-talk between ROS originating from mitochondria and NF- $\kappa B$ signaling pathways has been established and elucidated during the last two decades [52]. Based on a probable association between TRAILmediated apoptosis, mitochondrial function, NF-kB and STAT3, three main goals of the present study were: i) to determine how suppression of mitochondrial function affects TRAIL/TRAIL-Rmediated apoptosis; ii) to determine the role of changes in the pattern of NF-KB- and STAT3-directed transcription for regulation of apoptosis in mtDNA-depleted cells; iii) to determine effects of suppression of NF-KB- and STAT3-dependent gene expression that controls cell survival mechanisms in the parent $\rho^{+}$cells for modeling of deficiency of mitochondrial function.

The results of our study demonstrated a substantial upregulation of TRAIL and CHX induced apoptosis in mtDNA-depleted $\rho^{0}$ cells, compared with parental $\rho^{+}$cells. Gene expression analysis indicated that NF- $\kappa \mathrm{B}$-driven inflammatory signature genes (IL1 $\beta$, IL6, COX2, MMP3 and MMP12) exhibited decreased basal and radiation-induced expression in mtDNA-depleted cells. Furthermore, expression of NF- $\kappa$ B target antioxidant gene SOD2 was not upregulated in mtDNA-depleted cells $24 \mathrm{~h}$ after irradiation (Fig. 4A). Several NF- $\kappa B$ target cytokine genes, including IL6, further induced JAK2-STAT3 activation, providing a "vertical" connection between NF-אB and STAT3 [43]. Direct protein-protein interaction between NF- $\kappa$ B p65 and STAT3, demonstrated a "horizontal" association between two master transcription factors [58], which might additionally increase the complexity of regulatory mechanisms of cell survival. Furthermore, IL6-mediated signaling can activate NF- $\mathrm{B}$, establishing a positive feedback loop involving NF- $\mathrm{B}$, specific microRNAs and STAT3 that maintain inflammation and links inflammation to cell transformation [59].

Recent publications demonstrated a linkage of STAT3 expression with the mitochondrial respiration additionally confirming serious changes in STAT3 activation in $\rho^{0}$ cells $[60,61]$. Inhibition of IKK-NF- $\mathrm{B}$ and IL6-JAK2-STAT3 signaling pathways at different points caused an increase in TRAIL-R-mediated apoptosis in $\rho^{+}$ cells that could almost achieve the apoptotic levels observed in $\rho^{0}$ cells. Taken together, these results provide additional evidence of the critical role of NF- $\mathrm{B} / \mathrm{STAT} 3-$ dependent gene expression for the negative regulation of TRAIL/TRAIL-R-mediated apoptosis in the parent HSF, which is partially lost in mtDNA-depleted cells.

The final goal of our study was to explore the possibility of increasing the sensitivity of cancer cells to TRAIL/TRAIL-Rmediated apoptosis in conditions of partial suppression of the mitochondrial death pathway. We recently demonstrated for several human melanoma cell lines dramatically increased susceptibility to TRAIL by combined treatment of TRAIL with IKK $\beta-N F-K B$, JAK2-STAT3 inhibitors or with directly targeting mitochondrial function using sodium arsenite [62]. Due to the enormous genetic and epigenetic diversity of melanoma cells, such an approach probably could not be universal; even if it works successfully for many melanoma lines, characterized by average levels of surface expression of TRAIL-R and basal activation of NF$\kappa \mathrm{B}$, as well as for neuroblastoma cell lines. Furthermore, recent investigation demonstrated that a conditional knock-out of $I K K b$ inhibited melanoma development in mice [63] and there are several clinical trials of cancer treatment by TRAIL in a combination

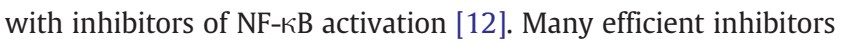
of JAK2-STAT3 were created in recent years, some of which demonstrated well pronounced anti-cancer effects [64]. Results of the present study and recently published paper [62] suggest usage of these inhibitors in combination with TRAIL for additional upregulation of apoptosis in cancer cells. On the other hand, widely used inhibition of the anti-apoptotic functions of the members of the Bcl-2 family for upregulation of the mitochondrial death pathway in cancer cells [11] appears to be a valuable approach for treatment of cancer cells with relatively mild and reversible suppression of mitochondrial function.

Global gene expression analysis of HSF performed in our study demonstrated significant changes in gene expression of 2100 nuclear genes involving in the regulation of numerous cellular functions after mitochondrial depletion. The main goal of the present study was focused on the problem of upregulation of the death receptor-mediated apoptosis in mtDNA-depleted cells in the context of suppression of NF- $\mathrm{KB}$ and STAT3 activation and downregulation of expression of NF- $\mathrm{B}$ - and STAT3 target genes with anti-apoptotic activity, such as PTGS2/COX2, Survivin and XIAP. However, our results of analysis of gene expression in mtDNAdepleted cells can be extensively used in the future studies on the fundamental role of mitochondria in the specific regulation of the nuclear gene expression. An arising role of mitochondria in the regulation of lifespan of the multicellular organisms [65] could be directly linked with results obtained in the present study, especially with regulation of nuclear pro-inflammatory gene expression directed by mitochondrial function.

The important clinical problem tightly linked with mitochondrial function is radiation response of human fibroblasts and its changes in mtDNA-depleted cells. We substantially extended our previous observations $[22,44]$, demonstrating multiple differential 
changes in gene expression following $\alpha$-irradiation in $\rho^{0}$ cells versus $\rho^{+}$cells. Interestingly, ionizing irradiation of normal HSF at low doses induced gene expression of numerous cytokines, growth factor and their receptors that were important for cell survival. In contrast, expressions of the same genes were substantially downregulated in mtDNA-deficient HSF providing conditions for upregulation of death-receptor-mediated apoptosis in these cells. The results obtained in the present study could be a basis for the future work linked with sensitization of cancer cells exhibiting suppressed mitochondrial function to radiation treatment, especially in the presence of inhibitors of PI3K-AKT signaling pathway or specific inhibitory mAbs for different cytokines with survival functions.

Supplementary materials related to this article can be found online at doi:10.1016/j.yexcr.2011.03.012.

\section{Acknowledgments}

We would like to thank Dr. Mercy Davidson for creation of mtDNAdepleted HSF and numerous advices regarding mitochondrial studies, Dr. Michael Partridge for his expertise and advices in mitochondrial investigations, Dr. Howard Lieberman for critical reading the manuscript and stimulating discussion, Mr. Stephen Marino and the Radiological Research Accelerator Facility (RARAF) staff for assistance with irradiations. RARAF is an NIH supported Resource Center through NIBIB grant EB-002033. This work was supported by NIH grant CA 49062, ES 012888 and EB 002033.

\section{REFERENCES}

[1] A. Ashkenazi, P. Holland, S.G. Eckhardt, Ligand-based targeting of apoptosis in cancer: the potential of recombinant human apoptosis ligand 2/tumor necrosis factor-related apoptosis-inducing ligand (rhApo2L/TRAIL), J. Clin. Oncol. 26 (2008) 3621-3630.

[2] Z. Jin, W.S. El-Deiry, Overview of cell death signaling pathways, Cancer Biol. Ther. 4 (2005) 139-163.

[3] A. Ashkenazi, Targeting death and decoy receptors of the tumour-necrosis factor superfamily, Nat. Rev. Cancer 2 (2002) $420-430$

[4] S. Fulda, K.M. Debatin, Sensitization for tumor necrosis factor-related apoptosis-inducing ligand-induced apoptosis by the chemopreventive agent resveratrol, Cancer Res. 64 (2004) 337-346.

[5] V.N. Ivanov, H. Zhou, T.K. Hei, Sequential treatment by ionizing radiation and sodium arsenite dramatically accelerates TRAIL-mediated apoptosis of human melanoma cells, Cancer Res. 67 (2007) 5397-5407.

[6] P. Hersey, X.D. Zhang, Treatment combinations targeting apoptosis to improve immunotherapy of melanoma, Cancer Immunol. Immunother. 58 (2009) 1749-1759.

[7] P. Costantini, E. Jacotot, D. Decaudin, G. Kroemer, Mitochondrion as a novel target of anticancer chemotherapy, J. Natl Cancer Inst. 92 (2000) 1042-1053.

[8] K.M. Debatin, P.H. Krammer, Death receptors in chemotherapy and cancer, Oncogene 23 (2004) 2950-2966.

[9] R.G. Jones, C.B. Thompson, Tumor suppressors and cell metabolism: a recipe for cancer growth, Genes Dev. 23 (2009) 537-548.

[10] V. Gogvadze, S. Orrenius, B. Zhivotovsky, Mitochondria as targets for cancer chemotherapy, Semin. Cancer Biol. 19 (2009) $57-66$.
[11] J.M. Adams, S. Cory, Bcl-2-regulated apoptosis: mechanism and therapeutic potential, Curr. Opin. Immunol. 19 (2007) 488-496.

[12] R.W. Johnstone, A.J. Frew, M.J. Smyth, The TRAIL apoptotic pathway in cancer onset, progression and therapy, Nat. Rev. Cancer 8 (2008) 782-798.

[13] V. Gogvadze, S. Orrenius, B. Zhivotovsky, Mitochondria in cancer cells: what is so special about them? Trends Cell Biol. 18 (2008) $165-173$.

[14] M.P. King, Y. Koga, M. Davidson, E.A. Schon, Defects in mitochondrial protein synthesis and respiratory chain activity segregate with the tRNA(Leu(UUR)) mutation associated with mitochondrial myopathy, encephalopathy, lactic acidosis, and strokelike episodes, Mol. Cell. Biol. 12 (1992) 480-490.

[15] M.D. Jacobson, J.F. Burne, M.P. King, T. Miyashita, J.C. Reed, M.C. Raff, Bcl-2 blocks apoptosis in cells lacking mitochondrial DNA, Nature 361 (1993) 365-369.

[16] J. Wang, J.P. Silva, C.M. Gustafsson, P. Rustin, N.G. Larsson, Increased in vivo apoptosis in cells lacking mitochondrial DNA gene expression, Proc. Natl Acad. Sci. U. S. A. 98 (2001) 4038-4043.

[17] K. Schulze-Osthoff, R. Beyaert, V. Vandevoorde, G. Haegeman, W. Fiers, Depletion of the mitochondrial electron transport abrogates the cytotoxic and gene-inductive effects of TNF, EMBO J. 12 (1993) 3095-3104.

[18] S. Jiang, J. Cai, D.C. Wallace, D.P. Jones, Cytochrome c-mediated apoptosis in cells lacking mitochondrial DNA. Signaling pathway involving release and caspase 3 activation is conserved, J. Biol. Chem. 274 (1999) 29905-29911.

[19] G. Santamaria, M. Martinez-Diez, I. Fabregat, J.M. Cuezva, Efficient execution of cell death in non-glycolytic cells requires the generation of ROS controlled by the activity of mitochondrial H+-ATP synthase, Carcinogenesis 27 (2006) 925-935.

[20] R. Dey, C.T. Moraes, Lack of oxidative phosphorylation and low mitochondrial membrane potential decrease susceptibility to apoptosis and do not modulate the protective effect of $\mathrm{Bcl}-\mathrm{x}(\mathrm{L})$ in osteosarcoma cells, J. Biol. Chem. 275 (2000) 7087-7094.

[21] S.Y. Park, I. Chang, J.Y. Kim, S.W. Kang, S.H. Park, K. Singh, M.S. Lee, Resistance of mitochondrial DNA-depleted cells against cell death: role of mitochondrial superoxide dismutase, J. Biol. Chem. 279 (2004) 7512-7520.

[22] H. Zhou, V.N. Ivanov, Y.C. Lien, M. Davidson, T.K. Hei, Mitochondrial function and nuclear factor-kappaB-mediated signaling in radiation-induced bystander effects, Cancer Res. 68 (2008) 2233-2240.

[23] S.X. Liu, M.M. Davidson, X. Tang, W.F. Walker, M. Athar, V. Ivanov, T.K. Hei, Mitochondrial damage mediates genotoxicity of arsenic in mammalian cells, Cancer Res. 65 (2005) 3236-3242.

[24] H. Zhou, G. Randers-Pehrson, C.A. Waldren, D. Vannais, E.J. Hall, T.K. Hei, Induction of a bystander mutagenic effect of alpha particles in mammalian cells, Proc. Natl Acad. Sci. U. S. A. 97 (2000) 2099-2104.

[25] G.W. Wright, R.M. Simon, A random variance model for detection of differential gene expression in small microarray experiments, Bioinformatics 19 (2003) 2448-2455.

[26] Y. Benjamini, Y. Hochberg, Controlling the false discovery rate - a practical and powerful approach to multiple testing, J. R. Stat. Soc. B Methodol. 57 (1995) 289-300.

[27] S.A. Ghandhi, B. Yaghoubian, S.A. Amundson, Global gene expression analyses of bystander and alpha particle irradiated normal human lung fibroblasts: synchronous and differential responses, BMC Med. Genomics 1 (2008) 63.

[28] J. Vandesompele, K. De Preter, F. Pattyn, B. Poppe, N. Van Roy, A. De Paepe, F. Speleman, Accurate normalization of real-time quantitative RT-PCR data by geometric averaging of multiple internal control genes, Genome Biol. 3 (2002).

[29] P.D. Thomas, M.J. Campbell, A. Kejariwal, H.Y. Mi, B. Karlak, R. Daverman, K. Diemer, A. Muruganujan, A. Narechania, PANTHER: a library of protein families and subfamilies indexed by function, Genome Res. 13 (2003) 2129-2141. 
[30] M.A. Partridge, S.X. Huang, E. Hernandez-Rosa, M.M. Davidson, T.K. Hei, Arsenic induced mitochondrial DNA damage and altered mitochondrial oxidative function: implications for genotoxic mechanisms in mammalian cells, Cancer Res. 67 (2007) 5239-5247.

[31] N. Erez, M. Truitt, P. Olson, S.T. Arron, D. Hanahan, Cancer-associated fibroblasts are activated in incipient neoplasia to orchestrate tumor-promoting inflammation in an NF-kappaB-dependent manner, Cancer Cell 17 (2010) 135-147.

[32] M.F. Alexeyev, S.P. Ledoux, G.L. Wilson, Mitochondrial DNA and aging, Clin. Sci. (Lond.) 107 (2004) 355-364.

[33] D.J. Dauer, B. Ferraro, L. Song, B. Yu, L. Mora, R. Buettner, S. Enkemann, R. Jove, E.B. Haura, Stat3 regulates genes common to both wound healing and cancer, Oncogene 24 (2005) 3397-3408.

[34] M. Snyder, X.Y. Huang, J.J. Zhang, Identification of novel direct Stat3 target genes for control of growth and differentiation, J. Biol. Chem. 283 (2008) 3791-3798.

[35] I.E. Wertz, K.M. O'Rourke, H. Zhou, M. Eby, L. Aravind, S. Seshagiri, P. Wu, C. Wiesmann, R. Baker, D.L. Boone, A. Ma, E.V. Koonin, V.M. Dixit, De-ubiquitination and ubiquitin ligase domains of A20 downregulate NF-kappaB signalling, Nature 430 (2004) 694-699.

[36] J.W. Kim, I. Tchernyshyov, G.L. Semenza, C.V. Dang, HIF-1-mediated expression of pyruvate dehydrogenase kinase: a metabolic switch required for cellular adaptation to hypoxia, Cell Metab. 3 (2006) 177-185.

[37] A.C. Groner, S. Meylan, A. Ciuffi, N. Zangger, G. Ambrosini, N. Denervaud, P. Bucher, D. Trono, KRAB-zinc finger proteins and KAP1 can mediate long-range transcriptional repression through heterochromatin spreading, PLoS Genet. 6 (2010) e1000869.

[38] S.A. Amundson, M.B. Grace, C.B. McLeland, M.W. Epperly, A. Yeager, Q. Zhan, J.S. Greenberger, A.J. Fornace Jr., Human in vivo radiation-induced biomarkers: gene expression changes in radiotherapy patients, Cancer Res. 64 (2004) 6368-6371.

[39] D.A. Smirnov, M. Morley, E. Shin, R.S. Spielman, V.G. Cheung, Genetic analysis of radiation-induced changes in human gene expression, Nature 459 (2009) 587-591.

[40] V.N. Ivanov, H. Zhou, S.A. Ghandhi, T.B. Karasic, B. Yaghoubian, S.A. Amundson, T.K. Hei, Radiation-induced bystander signaling pathways in human fibroblasts: a role for interleukin-33 in the signal transmission. Cell. Signal. 22 (2010) 1076-1087.

[41] V. Baud, M. Karin, Is NF-kappaB a good target for cancer therapy? Hopes and pitfalls, Nat. Rev. Drug Discov. 8 (2009) 33-40.

[42] M. Karin, A. Lin, NF-kappaB at the crossroads of life and death, Nat. Immunol. 3 (2002) 221-227.

[43] S. Grivennikov, M. Karin, Autocrine IL-6 signaling: a key event in tumorigenesis? Cancer Cell 13 (2008) 7-9.

[44] V.N. Ivanov, H. Zhou, S.A. Ghandhi, T.B. Karasic, B. Yaghoubian, S.A. Amundson, T.K. Hei, Radiation-induced bystander signaling pathways in human fibroblasts: a role for interleukin-33 in the signal transmission, Cell. Signal. 22 (2010) 1076-1087.

[45] E. Sahin, S. Colla, M. Liesa, J. Moslehi, F.L. Muller, M. Guo, M. Cooper, D. Kotton, A.J. Fabian, C. Walkey, R.S. Maser, G. Tonon, F. Foerster, R. Xiong, Y.A. Wang, S.A. Shukla, M. Jaskelioff, E.S. Martin, T.P. Heffernan, A. Protopopov, E. Ivanova, J.E. Mahoney, M. KostAlimova, S.R. Perry, R. Bronson, R. Liao, R. Mulligan, O.S. Shirihai, L. Chin, R.A. Depinho, Telomere dysfunction induces metabolic and mitochondrial compromise, Nature 470 (2011) 359-365.

[46] P.D. Boyer, The ATP synthase-a splendid molecular machine, Annu. Rev. Biochem. 66 (1997) 717-749.

[47] K.F. Ferri, G. Kroemer, Organelle-specific initiation of cell death pathways, Nat. Cell Biol. 3 (2001) E255-E263.

[48] R. Zhou, A.S. Yazdi, P. Menu, J. Tschopp, A role for mitochondria in NLRP3 inflammasome activation, Nature 469 (2011) 221-225.

[49] H. Pelicano, R.H. Xu, M. Du, L. Feng, R. Sasaki, J.S. Carew, Y. Hu, L. Ramdas, L. Hu, M.J. Keating, W. Zhang, W. Plunkett, P. Huang,
Mitochondrial respiration defects in cancer cells cause activation of Akt survival pathway through a redox-mediated mechanism, J. Cell Biol. 175 (2006) 913-923.

[50] J. Lu, L.K. Sharma, Y. Bai, Implications of mitochondrial DNA mutations and mitochondrial dysfunction in tumorigenesis, Cell Res. 19 (2009) 802-815.

[51] T.E. Froehlich, B.P. Lanphear, K.N. Dietrich, D.A. Cory-Slechta, N. Wang, R.S. Kahn, Interactive effects of a DRD4 polymorphism, lead, and sex on executive functions in children, Biol. Psychiatry 62 (2007) 243-249.

[52] C. Bubici, S. Papa, K. Dean, G. Franzoso, Mutual cross-talk between reactive oxygen species and nuclear factor-kappa B: molecular basis and biological significance, Oncogene 25 (2006) 6731-6748

[53] M. Karin, NF-kappaB as a critical link between inflammation and cancer, Cold Spring Harb. Perspect. Biol. 1 (2009) a000141.

[54] A. Kumar, Y. Takada, A.M. Boriek, B.B. Aggarwal, Nuclear factor-kappaB: its role in health and disease, J. Mol. Med. 82 (2004) 434-448.

[55] M. Kusaba, K. Nakao, T. Goto, D. Nishimura, H. Kawashimo, H. Shibata, Y. Motoyoshi, N. Taura, T. Ichikawa, K. Hamasaki, K. Eguchi, Abrogation of constitutive STAT3 activity sensitizes human hepatoma cells to TRAIL-mediated apoptosis, J. Hepatol. 47 (2007) 546-555.

[56] K. Kovalovich, W. Li, R. DeAngelis, L.E. Greenbaum, G. Ciliberto, R. Taub, Interleukin- 6 protects against Fas-mediated death by establishing a critical level of anti-apoptotic hepatic proteins FLIP, Bcl-2, and Bcl-xL, J. Biol. Chem. 276 (2001) 26605-26613.

[57] V.N. Ivanov, A. Bhoumik, M. Krasilnikov, R. Raz, L.B. Owen-Schaub, D. Levy, C.M. Horvath, Z. Ronai, Cooperation between STAT3 and c-jun suppresses Fas transcription, Mol. Cell 7 (2001) 517-528.

[58] J. Yang, X. Liao, M.K. Agarwal, L. Barnes, P.E. Auron, G.R. Stark, Unphosphorylated STAT3 accumulates in response to IL-6 and activates transcription by binding to NFkappaB, Genes Dev. 21 (2007) 1396-1408.

[59] D. Iliopoulos, H.A. Hirsch, K. Struhl, An epigenetic switch involving NF-kappaB, Lin28, Let-7 MicroRNA, and IL6 links inflammation to cell transformation, Cell 139 (2009) 693-706.

[60] D.J. Gough, A. Corlett, K. Schlessinger, J. Wegrzyn, A.C. Larner, D.E. Levy, Mitochondrial STAT3 supports Ras-dependent oncogenic transformation, Science 324 (2009) 1713-1716.

[61] J. Wegrzyn, R. Potla, Y.J. Chwae, N.B. Sepuri, Q. Zhang, T. Koeck, M. Derecka, K. Szczepanek, M. Szelag, A. Gornicka, A. Moh, S. Moghaddas, Q. Chen, S. Bobbili, J. Cichy, J. Dulak, D.P. Baker, A. Wolfman, D. Stuehr, M.O. Hassan, X.Y. Fu, N. Avadhani, J.I. Drake, P. Fawcett, E.J. Lesnefsky, A.C. Larner, Function of mitochondrial Stat3 in cellular respiration, Science 323 (2009) 793-797.

[62] V.N. Ivanov, M.A. Partridge, S.X. Huang, T.K. Hei, Suppression of the proinflammatory response of metastatic melanoma cells increases TRAIL-induced apoptosis, J. Cell. Biochem. 112 (2011) 463-475.

[63] J. Yang, R. Splittgerber, F.E. Yull, S. Kantrow, G.D. Ayers, M. Karin, A. Richmond, Conditional ablation of Ikkb inhibits melanoma tumor development in mice. J. Clin. Invest. 120 (2010) 2563-2574.

[64] M. Hedvat, D. Huszar, A. Herrmann, J.M. Gozgit, A. Schroeder, A. Sheehy, R. Buettner, D. Proia, C.M. Kowolik, H. Xin, B. Armstrong, G. Bebernitz, S. Weng, L. Wang, M. Ye, K. McEachern, H. Chen, D. Morosini, K. Bell, M. Alimzhanov, S. Ioannidis, P. McCoon, Z.A. Cao, H. Yu, R. Jove, M. Zinda, The JAK2 inhibitor AZD1480 potently blocks Stat3 signaling and oncogenesis in solid tumors, Cancer Cell 16 (2009) 487-497.

[65] J. Durieux, S. Wolff, A. Dillin, The cell-non-autonomous nature of electron transport chain-mediated longevity, Cell 144 (2011) 79-91. 